Review

\title{
GLP-1 receptor agonists (GLP-1RAs): cardiovascular actions and therapeutic potential
}

\author{
Xiaoxuan Ma1 ${ }^{1}$, Zhenghong Liu ${ }^{1}$, Iqra Ilyas ${ }^{1}$, Peter J. Little ${ }^{2,3}$, Danielle Kamato ${ }^{3}$, Amirhossein Sahebka ${ }^{4,5}$, \\ Zhengfang Chen ${ }^{6}$, Sihui Luo ${ }^{1}$, Xueying Zheng1, Jianping Weng ${ }^{1 凶}$, Suowen $\mathrm{Xu}^{1 凶}$ \\ 1. Institute of Endocrine and Metabolic Diseases, The First Affiliated Hospital USTC, Division of Life Sciences and Medicine, University of Science and \\ Technology of China, Hefei, 230001, China. \\ 2. Sunshine Coast Health Institute, University of the Sunshine Coast, Birtinya, QLD 4575, Australia. \\ 3. School of Pharmacy, Pharmacy Australia Centre of Excellence, the University of Queensland, Woolloongabba, Queensland 4102, Australia. \\ 4. Halal Research Center of IRI, FDA, Tehran, Iran. \\ 5. Biotechnology Research Center, Pharmaceutical Technology Institute, Mashhad, Iran. \\ 6. Changshu Hospital Affiliated to Soochow University, Changshu No.1 People's Hospital, Changshu 215500, Jiangsu Province, China. \\ $\triangle$ Corresponding authors: Suowen Xu, PhD or Jianping Weng, MD, PhD, E-mail: sxu1984@ustc.edu.cn or wengjp@ustc.edu.cn.
}

(C) The author(s). This is an open access article distributed under the terms of the Creative Commons Attribution License (https://creativecommons.org/licenses/by/4.0/). See http://ivyspring.com/terms for full terms and conditions.

Received: 2021.03.01; Accepted: 2021.04.28; Published: 2021.05.11

\begin{abstract}
Type 2 diabetes mellitus (T2DM) is closely associated with cardiovascular diseases (CVD), including atherosclerosis, hypertension and heart failure. Some anti-diabetic medications are linked with an increased risk of weight gain or hypoglycemia which may reduce the efficacy of the intended anti-hyperglycemic effects of these therapies. The recently developed receptor agonists for glucagon-like peptide-1 (GLP-1RAs), stimulate insulin secretion and reduce glycated hemoglobin levels without having side effects such as weight gain and hypoglycemia. In addition, GLPI-RAs demonstrate numerous cardiovascular protective effects in subjects with or without diabetes. There have been several cardiovascular outcomes trials (CVOTs) involving GLP-IRAs, which have supported the overall cardiovascular benefits of these drugs. GLPI-RAs lower plasma lipid levels and lower blood pressure (BP), both of which contribute to a reduction of atherosclerosis and reduced CVD. GLP-IR is expressed in multiple cardiovascular cell types such as monocyte/macrophages, smooth muscle cells, endothelial cells, and cardiomyocytes. Recent studies have indicated that the protective properties against endothelial dysfunction, anti-inflammatory effects on macrophages and the anti-proliferative action on smooth muscle cells may contribute to atheroprotection through GLP-1R signaling. In the present review, we describe the cardiovascular effects and underlying molecular mechanisms of action of GLP-1RAs in CVOTs, animal models and cultured cells, and address how these findings have transformed our understanding of the pharmacotherapy of T2DM and the prevention of CVD.
\end{abstract}

Key words: GLP-1RAs; CVD; diabetes; CVOT; glycemic control; MACE

\section{Introduction}

Over $90 \%$ of diabetes is classified into two main types being Type 1 diabetes mellitus (T1DM) and T2DM. T1DM is defined as an autoimmune disease, resulting in insulin deficiency. T2DM is a metabolic disease caused by acquired endocrine disorders. T2DM is the underlying cause of many complications, among which, cardiovascular diseases (CVDs) are mainly responsible for the high rates of morbidity and mortality. Atherosclerotic CVD manifest as heart attacks and strokes, is responsible for up to 85 per cent of cardiovascular deaths [1]. Atherosclerosis emerges as the "invisible killer" lurking in the cardiovascular system. With the gradual progression of atherosclerotic plaques, atherosclerosis will induce angina pectoris, or cerebral ischemia, leading to severe clinical manifestations such as heart failure, myocardial infarction (MI), cerebral infarction and lower limb ischemia and amputation [2].

Multi-country, multi-center long-term cardiovascular outcome trials (CVOTs) confirmed that GLP-1RAs decrease cardiovascular mortality and provide cardiovascular benefits to reduce the 
incidence of MI or non-fatal stroke [3]. For example, in the LEADER trial, when compared with placebo, liraglutide decreased the incidence of major cardiovascular events (MACE) by $13 \%$, cardiovascular death by $22 \%$ and all-cause death by $15 \%$ among T2DM patients with CVD, on a standard treatment basis [4]. In addition, liraglutide provided multiple additional benefits by reducing the incidence of hypoglycemia, lowering $\mathrm{HbA} 1 \mathrm{c}$ and functioning through multiple mechanisms to better control multiple causes of MACE, such as blood lipids, BP as well as body weight (BW).

GLP-1 is a gut-derived insulin agonist with the ability to suppress glucagon release and stimulate insulin secretion through targeting a-cells and $\beta$-cells, respectively [5]. Likewise, GLP-1RAs can lower postprandial glycemia predominantly by slowing gastric emptying and promoting weight loss $[6,7]$. GLP-1RAs may improve endothelial cell function via anti-inflammatory and vasodilatory properties. Also, anti-proliferative effects on smooth muscle cells and anti-inflammatory effects on macrophages may contribute to the protection against the development and progression of atherosclerosis [8-10]. In consideration of the dual roles of GLP-1RAs in hypoglycemic effects and preventing CVD among T2DM patients, we reviewed the cardiovascular effects and molecular mechanisms of GLP-1RAs in CVOTs, animal models and cultured cells, and discuss how these findings transform pharmacotherapies for T2DM, and even expand the indication of this important category of anti-diabetic drugs to CVD patients without diabetes.

\section{Clinical GLP-1RAs and their pharmacological basis of action}

GLP-1RAs, consist of short-acting and long-acting agents. Short-acting drugs include exenatide twice daily, lixisenatide once daily and oral semaglutide once daily, while long-acting drugs include liraglutide, semaglutide, exenatide, albiglutide and dulaglutide all being administered once weekly. The primary pharmacodynamic distinctions between long-acting and short-acting GLP-1RAs are that long-acting agonists augment insulin production and suppress glucagon generation to lower postprandial glucose and fasting plasma glucose, while short-acting agonists chiefly lower postprandial glucose by delaying gastric emptying. Long-acting GLP-1RAs also have other benefits including improved gastrointestinal tolerability, moderate plasma drug concentration fluctuations, and more convenient dosage regimens which may improve medication adherence and treatment outcomes [11] (Table 1).
Table 1. Current GLP-IRAs in the clinic

\begin{tabular}{llll}
\hline GLP-1RAs & Classification & $\begin{array}{l}\text { Frequency of } \\
\text { administration }\end{array}$ & Half-life $\left(\mathrm{t}_{1 / 2}\right)$ \\
\hline Lixisenatide & Short-acting & Once daily & $3 \mathrm{~h}$ \\
Oral semaglutide & Short-acting & Once daily & $\approx 1$ week \\
Exenatide & Short-acting & Twice daily/ & $2.4 \mathrm{~h} /$ Sustained- \\
& Long-acting & Once weekly & release \\
Liraglutide & Long-acting & Once daily & $13 \mathrm{~h}$ \\
Semaglutide & Long-acting & Once weekly & $\approx 1$ week \\
Albiglutide & Long-acting & Once weekly & $\approx 5$ days \\
Taspoglutide & Long-acting & Once weekly & $\approx 1$ week \\
Dulaglutide & Long-acting & Once weekly & $4.5-4.7$ days \\
\hline
\end{tabular}

Exendin- 4 was originally found in the saliva of the venomous lizards whose synthetic version is exenatide. Exendin- 4 inhibits the remodeling in the remote myocardium of rats following acute MI by attenuating $\beta$-catenin activation and activating glycogen synthase kinase- 3 , $\beta$-arrestin- 2 and protein phosphatase 2A [12]. In addition, exendin-4 protects against cardiac ischemia/reperfusion injury in rats by enhancing antioxidant levels and inhibiting c-Jun NH2-terminal kinase (JNK)/ $\mathrm{p}^{66}$ Shc/NADPH oxidase axis [13]. GLP-1RAs, such as lixisenatide, not only rely on $\beta$-cell function and glucagon suppression, but also assist to lower glucose by other (insulin-independent) mechanisms such as delayed gastric emptying, underlying the clinical utility of GLP-1RAs as adjuvant therapy to basal insulin in longstanding T2DM [14]. Further, liraglutide protects against vascular oxidative stress via attenuating eNOS (endothelial NO synthase) s-glutathionylation (a hallmark of eNOS uncoupling) and increasing $\mathrm{NO}$ bioavailability [15].

The GLP-1 analogs, semaglutide and liraglutide, delay the progression of atherosclerosis by regulating inflammatory pathways in low-density lipoprotein receptor-deficient (LDLr/-) and apolipoprotein E-deficient (ApoE-/) mice [16]. Oral semaglutide reduces systolic blood pressure (SBP), BW and blood glucose levels. Nevertheless, it is associated with increased incidence of gastrointestinal adverse reactions [17]. Exenatide ameliorates intramyocellular lipid deposition through improving insulin sensitivity and activating the AMP-activated protein kinase (AMPK) signaling pathway without BW reduction [18]. Compared with twice-daily exenatide, dulaglutide treatment reduces glycated hemoglobin and fasting plasma glucose (FPG) to a greater extent [19]. Taspoglutide prevents apoptosis in vitro, promotes $\beta$-cell proliferation, and exerts multiple protective effects of $\beta$-cell in Zucker Diabetic Fatty rats [20]. Compared with both placebo and liraglutide at 26 weeks, orally bioavailable semaglutide is superior in reducing BW and non-inferior to liraglutide concerning for decreasing $\mathrm{HbA1c}$ [21]. 
Based on the above pharmacological characteristics of categories of GLP-1RAs agents, despite slight adverse gastrointestinal side effects, it is clear that GLP-1RAs agents have efficacy in cardiovascular protection without untoward hypoglycemia.

\section{Cardiovascular outcome trials of GLP-1RAs}

In the past decade, CVOTs with GLP-1RAs have been conducted with at least seven agents including liraglutide, lixisenatide, exenatide, semaglutide, dulaglutide, albiglutide and oral semaglutide (Table 2). In CVOTs, liraglutide, semaglutide and dulaglutide demonstrated appreciable cardiovascular and renal protective effects, among which liraglutide had an appreciable effect on mitigating the risk of cardiovascular death [4], while semaglutide and dulaglutide conferred a risk reduction on non-fatal stroke [22, 23]. Moreover, liraglutide also had effects on reducing the incidence of MI in high-risk patients for T2DM, and may improve the clinical outcomes of MI [24].

To date, the REWIND study has demonstrated for the first time that primary cardiovascular prevention strategies can significantly reduce cardiovascular adverse events in patients with T2DM, regardless of whether or not these patients are co-diagnosed with CVD [23]. In this regard, dulaglutide is an ideal hypoglycemic drug for patients with T2DM due to its reported utility in primary prevention and secondary prevention. By February 21, 2020, dodecaplatin ${ }^{\circledR}$ (dulaglutide) is the first and only FDA-approved anti-diabetic drug for primary and secondary prevention to alleviate the risk of MACE [25].

\section{Hyperglycemia}

All five long-acting GLP-1RAs can reduce glucose levels and BW [4, 22, 23, 26, 27]. In SUSTAIN 3, SUSTAIN 7 and SUSTAIN 10, the GLP-1RAs semaglutide reduced $\mathrm{HbA1}$ c by up to $1.8 \%$, achieved the glycemic control target of $\mathrm{HbA1c}$ in $80 \%$ of the intervention group, and reduced BW by up to $6.5 \mathrm{~kg}$, outcomes which were superior to liraglutide, exenatide and dulaglutide [28-30]. In the LEAD-5 trial, liraglutide (1.8 $\mathrm{mg}$ once daily) reduced $\mathrm{HbA1c}$ more than insulin glargine during the treatment period (26 weeks) [31]. The results of AWARD-CHN2 showed that the reduction of FPG by dulaglutide was similar to insulin glargine. In addition, post-prandial blood glucose reduction by dulaglutide was superior to insulin glargine. In addition to this, dulaglutide can greatly stabilize and decrease blood glucose levels [32].

\section{Atherosclerosis and coronary artery disease}

The levels of $\mathrm{HbA1c}$, dyslipidemia, BW and BP are several of the risk factors for the progression of atherosclerosis and CVD in patients with T2DM. Several clinical trials have demonstrated that most of GLP-1RAs improve these parameters and thus attenuate the development and progression of atherosclerosis, especially concerning low-density lipoprotein cholesterol (LDL-C) levels [33]. In 2015, a randomized controlled trial showed that taspoglutide can reduce total cholesterol, LDL-C and triglycerides [34]. Among new-onset patients with diabetes receiving standard statin therapy, liraglutide together with metformin improved lipid distribution of LDL and C-reactive protein (CRP) in atherosclerosis [35]. Studies have also reported that under the conditions of comparable glycemic control, liraglutide (1.2 $\mathrm{mg} / \mathrm{d}$ ) alone was more effective than liraglutide with metformin or metformin alone on lipid metabolism and cardiovascular protection [36].

Table 2. Cardiovascular outcome trials (CVOTs) of GLP-IRAs

\begin{tabular}{|c|c|c|c|c|c|c|c|}
\hline \multirow[t]{2}{*}{ GLP-1RAs } & \multirow[t]{2}{*}{ Trails } & \multirow[t]{2}{*}{ Patients } & \multirow{2}{*}{$\begin{array}{l}\text { Median duration of } \\
\text { follow-up }\end{array}$} & \multicolumn{3}{|l|}{ Outcomes } & \multirow[t]{2}{*}{ References } \\
\hline & & & & MACE & CV Death & $\mathrm{HHF}$ & \\
\hline Lixisenatide & $\begin{array}{l}\text { ELIXA } \\
\text { NCT01147250 }\end{array}$ & $\begin{array}{l}6068 \text { T2DM patients recently } \\
\text { suffering acute coronary } \\
\text { syndrome }\end{array}$ & 2.1 & $1.02(0.89-1.17)$ & $0.98(0.78-1.22)$ & $0.96(0.75-1.23)$ & [47] \\
\hline Liraglutide & $\begin{array}{l}\text { LEADER } \\
\text { NCT01179048 }\end{array}$ & $\begin{array}{l}9340 \text { T2DM patients with } \\
\text { CV risk factors or CVD }\end{array}$ & 3.8 & $0.87(0.78-0.97)$ & $0.78(0.66-0.93)$ & $0.87(0.73-1.05)$ & {$[4]$} \\
\hline Semaglutide & $\begin{array}{l}\text { SUSTAIN-6 } \\
\text { NCT01720446 }\end{array}$ & $\begin{array}{l}3297 \text { T2DM patients with } \\
\text { CV risk factors or CVD }\end{array}$ & 2.1 & $0.74(0.58-0.95)$ & $0.98(0.65-1.48)$ & $1.11(0.77-1.61)$ & [22] \\
\hline Exenatide & $\begin{array}{l}\text { EXSCEL } \\
\text { NCT01144338 }\end{array}$ & $\begin{array}{l}14752 \text { T2DM patients with } \\
\text { CV risk factors or CVD }\end{array}$ & 3.2 & $0.91(0.83-1.00)$ & $0.88(0.76-1.02)$ & $0.94(0.78-1.13)$ & [26] \\
\hline Albiglutide & $\begin{array}{l}\text { Harmony Outcomes } \\
\text { NCT02465515 }\end{array}$ & $\begin{array}{l}9463 \text { T2DM patients with } \\
\text { high CV risk. }\end{array}$ & 1.6 & $0.78(0.68-0.90)$ & $0.93(0.73-1.19)$ & $0.85(0.70-1.04)$ & [27] \\
\hline Dulaglutide & $\begin{array}{l}\text { REWIND } \\
\text { NCT01394952 }\end{array}$ & $\begin{array}{l}9901 \text { T2DM patients with } \\
\text { CV risk factors or CVD }\end{array}$ & 5.4 & 0.88 (0.79-0.99) & $0.91(0.78-1.06)$ & $0.93(0.77-1.12)$ & [23] \\
\hline $\begin{array}{l}\text { Oral } \\
\text { semaglutide }\end{array}$ & $\begin{array}{l}\text { PIONEER } 6 \text { Clinical } \\
\text { Trials } \\
\text { NCT02692716 }\end{array}$ & $\begin{array}{l}3183 \text { patients, most had } \\
\text { cardiovascular or chronic } \\
\text { kidney disease }\end{array}$ & 1.3 & $0.79(0.57-1.11)$ & $0.49(0.27-0.92)$ & $0.86(0.48-1.44)$ & {$[52]$} \\
\hline
\end{tabular}




\section{Hypertension}

In the LEAD series of studies, clinical data demonstrated that treatment with liraglutide for 26 weeks can reduce SBP [4]. Exenatide improved the BP and blood lipid level of T2DM patients for 7 consecutive years in a DURATION open-extension study [37]. In the REWIND study and AWARD5 study, dulaglutide consistently improved BP and lipid levels in patients [23, 38]. Mechanistically, GLP-1 can lower BP through a diuretic mechanism, and other effects on the kidneys $[39,40]$. At another level, GLP-1RAs also improve systemic insulin sensitivity to lower arterial hypertension in T2DM by decreasing the concentration of angiotensin II (Ang II) [41, 42].

\section{Heart failure}

There are two main trials (FIGHT and LIVE trials) demonstrating that treatment with liraglutide increased the risk of adverse heart failure-associated outcomes in patients with heart failure and reduced LVEF [43-45]. In the LIVE trial, liraglutide treatment resulted in no change in left ventricular systolic function, whereas liraglutide related to an increase in heart rate and more serious cardiac adverse events among chronic heart failure patients with and without type 2 diabetes [45]. While in a FIGHT trial, liraglutide reduced HbA1c levels $(-0.48 ; 95 \%$ CI $-0.92,-0.04$; $\mathrm{P}=$ $0.033)$ and triglyceride levels compared with placebo $(-33.1 \mathrm{mg} / \mathrm{dL} ; 95 \% \mathrm{CI}-60.7,-5.6 ; \mathrm{P}=0.019)$, together with a substantial weight reduction $(-4.10 \mathrm{lbs} ; 95 \% \mathrm{CI}$ -7.94, -0.25; $\mathrm{P}=0.0367$ ) [44]. Curiously, LEADER revealed a downward trend in hospitalization rates for heart failure $(-13 \%, \mathrm{P}=0.14)$ [4].

\section{Chronic kidney disease (CKD)}

CKD is clinically characterized by a decline in glomerular filtration rate (GFR) and proteinuria for diabetic nephropathy, which is determined by the pathological changes in the structure and function in the kidney of patients with T2DM. Several recent CVOTs have shown that GLP-1RAs can reduce the decline of estimated GFR (eGFR) and delay the onset of the occurrence of proteinuria in patients with T2DM $[4,22,26,46,47]$.

In the ELIXA trial, lixisenatide ameliorated macroalbuminuria assessed as a decline in the urinary albumin-to-creatinine ratio. An analysis of the ELIXA trial data indicated that short-term GLP-1RAs may also have renal protective effects, analogous to long-acting GLP-1RAs [47]. Analysis of the LEADER trial data demonstrated that liraglutide exerted a $22 \%$ decline in the morbidity of newly diagnosed or aggravated nephropathy [4]. While in SUSTAIN-6, a sharper decline $(46 \%)$ in macroalbuminuria seems to be entirely due to the semaglutide treatment than a
$26 \%$ fall in macroalbuminuria by liraglutide [22]. The AWARD-7 trial, which was the first clinical trial among moderate-to-severe CKD and T2DM displayed convincing protective effects on eGFR after treatment with GLP-1RAs [46]. In addition, the analysis of the EXSCEL trial revealed that a composite end-point of new macroalbuminuria, 40\% eGFR decline or renal death was reduced by the addition of exenatide in T2DM [26].

To summarize several meta-analyses of CVOTs conducted with GLP-1RAs, it isconfirmed that based on 43 trials, GLP-1RAs are a class of efficacious agent for reducing MACE (MH-OR 0.87 [0.83, 0.92]), cardiovascular and all-cause mortality (MH-OR 0.89 $[0.83,0.96])$ [48]. Further, GLP-1RAs significantly reduce the risk of $\mathrm{MI}$ and stroke, but have a neutral effect on hospitalization for heart failure upon 5 available CVOTs [49]. Meta-analysis of 7 CVOT pooled demonstrated that GLP-1RAs were associated with a similar decrease in MACE regardless of gender [50]. From one hundred and thirteen available trials, the safety of GLP-1RAs was confirmed in pancreatitis. Conversely, treatment with GLP-1RAs can increase cholelithiasis mobility [51].

\section{Cardiovascular actions of GLP-1RAs in pre-clinical studies}

\section{Effects of GLP-1RAs on atherosclerosis and atherosclerosis in the setting of diabetes}

Atherosclerosis with multiple and diverse drivers is a dominant complicating process in T2DM [53]. Exposure to western diets pathologically alters the expression of many genes leading to atherosclerosis [16]. According to a recent study, GLP-1R is mainly expressed in the macrophage enrichment region of atherosclerotic plaques, which provide us a new perspective on pharmacological modification of GLP-1R upon signal in atherosclerosis [54].

Preclinical studies have shown that large doses of GLP-1RAs can reduce lipid deposition and plaque volume on the aortic surface of hyperglycemic mice via an AMPK-independent action in streptozotocin (STZ)-induced hyperglycemic and hyperlipidemic mice or type 1 diabetic rats [55]. GLP-1RAs have direct anti-atherosclerotic effects in euglycemic mice, ApoE-/- mice or Watanabe heritable hyperlipidemic (WHHL) rabbits in a GLP-1R-dependent manner [56-58]. Therefore, these studies demonstrated that GLP-1RAs have an impact on preventing and stabilizing atherosclerotic vascular disease, which may translate into its protective effects against MACE in human subjects [59]. 
GLP-1RAs suppress the progression of atherosclerosis in ApoE $/ /, \mathrm{LDLr}^{-/-}$, and even in moderate uremia $\mathrm{LDLr}^{-}-$mice[16, 60]. This suppression is independent of plasma cholesterol changes and BW reduction through regulating markers of plaque instability and inflammation including those linked to plaque hemorrhage (CD163), matrix turnover (matrix metalloproteinase (MMP)-3, MMP-13), cholesterol metabolism (prostaglandin I2 synthase (PTGIS), ATP-binding cassette transporter 1 (ABCA1)), leukocyte recruitment (C-C motif chemokine ligand 2 (CCL2), osteopontin (OPN), interleukin (IL)-6), and leukocyte rolling, extravasation and adhesion (vascular cell adhesion molecule (VCAM)-1, E-selectin (SELE)) [16]. Moreover, GLP-1RAs can alleviate vascular remodeling expressed as neointimal hyperplasia after induced vascular injury. Specifically, GLP-1RAs can suppress vascular smooth muscle cell (VSMC) proliferation and migration via the cAMP/PKA pathway in C57BL/6 mice [61]. These findings indicate that GLP-1RAs limit and stabilize the development of atherosclerotic plaques through anti-inflammatory mechanisms and by preventing vascular remodeling [62].

GLP-1RAs attenuate the activation and recruitment of macrophages into the endothelium [63]. Treatment with GLP-1RAs can reduce monocyte/macrophage accumulation in the arterial wall by inhibiting the adhesion of monocytes to activated endothelium from the arteries of C57BL/ 6 mice as well as in ApoE-/- mice [64]. GLP-1RAs can also exert anti-inflammatory effects on macrophages as well as regulating macrophage phenotype [65]. For example, treatment of murine macrophages with GLP-1RAs in vitro inhibits monocyte chemoattractant protein-1 gene expression and p65 as well as tumor necrosis factor (TNF)- $\alpha$ expression. Moreover, GLP1RAs can suppress atherosclerosis in T2DM (STZ treated) rats by inhibiting macrophage infiltration and apoptosis [66]. The above studies suggest that GLP1RAs may be a valuable strategy for the treatment of atherosclerosis (Figure 1) (Table 3).

\section{Effects of GLP-1RAs on hypertension}

Hypertension and accompanying cardiovascular remodeling are amongst the leading drivers of atherosclerosis and causes of CVD. Endogenous GLP-1R signaling exerts a physiologically relevant effect on BP control, which may be attributable, in part, to its tonic actions on proximal tubule $\mathrm{Na} / \mathrm{H}$ mediated sodium reabsorption, and the intrarenal renin-angiotensin II system [67]. In spontaneously hypertensive rats, GLP-1 treatment mediates renal vasodilation and attenuates renal autoregulatory responses [68]. In addition, acute renal infusion with GLP-1 can augment renal blood flow and promote natriuresis and dieresis [69]. In summary, GLP-1 or GLP-1RA treatment can make a positive impact on reducing the impact of hypertension in affected patients (Figure 1).

\section{Effects of GLP-1RAs on myocardial infarction (MI)}

MI and its consequent tissue damage leading to heart failure are mainly responsible for the fatality in patients with T2DM. Evidence indicates that GLP1RAs can reduce the occurrence of MI [70]. Among patients with acute MI undergoing percutaneous interventions, GLP-1 treatment can reduce infarct size, together with improving left ventricular ejection fraction (LVEF) [71]. GLP-1RA (such as exendin-4) treatment can reduce the size of MI impacted cardiac volume in rats, inhibit ventricular dilation, myocardial fibrosis and hypertrophy in vivo [72]. Mechanically, GLP-1RAs regulate insulin-like growth factor- $1 / 2$ and upregulate a-estrogen receptors to exert cardioprotective actions in isoprenaline-induced MI [73]. In addition, another report demonstrated the reparative role of GLP-1RAs in MI via modulating sirtulin (SIRT)1/Parkin/mitophagy [74]. Interestingly, even in obese swine, GLP-1R activation can improve cardiac function and augment cardiac output after MI [75]. Accordingly, it is suggested that GLP-1RAs have properties of alleviating MI and repairing damaged cardiac tissue to improve cardiac function (Figure 1).

\section{Effects of GLP-1RAs on heart failure}

Myocardial remodeling has a critical role in heart failure following MI. Disturbances in cardiac calcium metabolism are a hallmark of heart failure. GLP-1RAs prevent post-MI remodeling by having an impact on the extracellular matrix changes rather than dependency on its glycemic control [76]. There is another mechanism showing that GLP-1RA treatment regulates $\mathrm{Ca}^{2+}$ levels due to reductions in the ryanodine receptor (RyR)2 phosphorylation and suppression of the activation of calmodulindependent protein kinase (CaMK)-II [77]. Moreover, a favorable impact of GLP-1RAs on cardiac remodeling can occur through activation of the eNOS/cyclic guanosine monophosphate (cGMP)/protein kinase $\mathrm{G}$ (PKG) nexus [72].

Cardiac hypertrophy leads to heart failure at the later decompensated stage of the disease process, which is a primary cause of morbidity and mortality. Evidence has recently revealed that GLP-1RAs inhibit cardiac hypertrophy by upregulating GLP-1R expression and activating the $\mathrm{AMPK} /$ mechanistic 
target of the rapamycin (mTOR) signaling pathway [78].

Mitochondrial dysfunction, apoptosis and oxidative stress are in part due to methylglyoxal accumulation. Therefore, the attenuation of methylglyoxal-induced mitochondrial abnormalities may suppress the progression of heart failure. In cultured H9c2 cells, GLP-1RAs attenuate the production of mitochondrial and intracellular reactive oxygen species (ROS) induced by methylglyoxal. As a result, GLP-1RAs display suppressive effects on mitochondrial functions and oxidative stress on heart failure [79].

Although GLP-1RAs can play a favorable role in improving heart failure based on pre-clinical studies, whereas some clinical evidence relevantly have reported that GLP-1RAs treatment could be associated with adverse heart failure events, eg. increasing heart rate, reducing LVEF [43-45]. Therefore, overall, the benefit of GLP-1RAs for heart failure has been difficult to confirm (Figure 1).

Table 3. Cardiovascular effects and mechanisms of GLP-IRAs in rodents

\begin{tabular}{|c|c|c|c|c|}
\hline Drugs & Animal model & Treatment dose and duration & Observations and mechanism & References \\
\hline Lixisenatide & $\begin{array}{l}\text { ApoE-/-Irs2 +/- mice with } \\
\text { atherogenic diet }\end{array}$ & $\begin{array}{l}10 \mu \mathrm{g} / \mathrm{kg} / \text { day via osmotic minipumps } \\
\text { for one month }\end{array}$ & $\begin{array}{l}\text { atheroma plaque size } \downarrow \\
\text { M2 phenotype } \downarrow \text { inflammation } \downarrow \\
\text { IL-6 } \downarrow ; \text { STAT3 } \downarrow \text { STAT1 } \downarrow \text {; NOS } \downarrow\end{array}$ & [91] \\
\hline Lixisenatide & $\begin{array}{l}\text { Watanabe heritable } \\
\text { hyperlipidemic }(\mathrm{WHHL}) \\
\text { rabbits }\end{array}$ & $\begin{array}{l}30 \mathrm{nmoL} / \mathrm{kg} / \text { day via osmotic pumps } \\
\text { for } 3 \text { month }\end{array}$ & $\begin{array}{l}\text { plaque stabilization } \uparrow \text {; plaque progression } \downarrow \\
\text { modifying plaque composition } \\
\text { inhibiting plaque growth }\end{array}$ & {$[58]$} \\
\hline Liraglutide & $\begin{array}{l}\text { ApoE-/- and LDLr } / \text { - mice with } \\
\text { a western diet }\end{array}$ & $\begin{array}{l}1 \mathrm{mg} / \mathrm{kg} / \text { day subcutaneously in } \\
\text { ApoE-/- mice for almost } 3 \text { months or } \\
\text { LDLr-/- mice for almost one month }\end{array}$ & $\begin{array}{l}\text { atherosclerosis } \downarrow \\
\text { Inflammatory Pathways }\end{array}$ & {$[16]$} \\
\hline Liraglutide & $\begin{array}{l}\text { Moderately uremic } \mathrm{LDLr}^{-/}- \\
\text {mice with a western diet }\end{array}$ & $\begin{array}{l}1000 \mu \mathrm{g} / \mathrm{kg} / \text { day for } 11 \text { weeks } \\
\text { via injections }\end{array}$ & $\begin{array}{l}\text { atherosclerosis } \downarrow \text {; kidney inflammation } \downarrow \\
\text { infiltration of CD4+ and CD8+ T cells } \downarrow\end{array}$ & {$[60]$} \\
\hline Liraglutide & ApoE-/- with a high-fat diet & $\begin{array}{l}400 \mu \mathrm{g} / \mathrm{kg} / \text { day via osmotic pumps for } \\
\text { one month }\end{array}$ & $\begin{array}{l}\text { atherosclerosis } \downarrow \text {; VSMCs proliferation } \downarrow \\
\text { AMPK signaling } \uparrow \text {; cells in G2/M } \downarrow\end{array}$ & {$[56]$} \\
\hline Liraglutide & $\begin{array}{l}\text { ApoE-/- mice with a fat-rich } \\
\text { diet }\end{array}$ & $\begin{array}{l}300 \mu \mathrm{g} / \mathrm{kg} / \text { daily for one month via } \\
\text { injections }\end{array}$ & $\begin{array}{l}\text { atherosclerosis } \downarrow \\
\text { proinflammatory immune cell and mediators } \downarrow \\
\text { marrow-derived macrophages } \uparrow\end{array}$ & [92] \\
\hline Liraglutide & $\begin{array}{l}\text { T2DM rats with a high fat diet } \\
\text { and small dosage } \\
\text { streptozotocin injection }\end{array}$ & $\begin{array}{l}200 \mu \mathrm{g} / \mathrm{kg} / \text { day } \\
\text { for } 3 \text { months via percutaneous } \\
\text { injections }\end{array}$ & $\begin{array}{l}\text { diabetic atherosclerosis } \downarrow \\
\text { microvesicles production, macrophage apoptosis, and ER } \\
\text { stress } \downarrow\end{array}$ & {$[66]$} \\
\hline Liraglutide & $\begin{array}{l}\text { Ldlr-/- mice with a western } \\
\text { diet }\end{array}$ & $\begin{array}{l}1 \mathrm{mg} / \mathrm{kg} / \text { day subcutaneously for one } \\
\text { month }\end{array}$ & $\begin{array}{l}\text { endothelial dysfunction } \downarrow \text {; inflammation } \downarrow \text { regulation of } \\
\text { vascular remodelling }\end{array}$ & {$[62]$} \\
\hline Liraglutide & ApoE-/- mice & $\begin{array}{l}107 \mathrm{nmol} / \mathrm{kg} / \text { day via osmotic pumps } \\
\text { for one month }\end{array}$ & $\begin{array}{l}\text { atherosclerosis } \downarrow \text {; foam cell formation } \downarrow \\
\text { ACAT1 } \downarrow\end{array}$ & [93] \\
\hline Liraglutide & $\begin{array}{l}\text { ApoE-/- mice with a high-fat } \\
\text { and -cholesterol diet }\end{array}$ & $\begin{array}{l}300 \mu \mathrm{g} / \mathrm{kg} / \text { day via subcutaneous } \\
\text { injections for } 6 \text { weeks }\end{array}$ & $\begin{array}{l}\text { atherosclerotic lesion formation } \downarrow \\
\text { MФ1-like monocytes and macrophages } \downarrow \\
\text { МФ2 } \uparrow\end{array}$ & {$[65]$} \\
\hline Liraglutide & T1DM rats with STZ & $\begin{array}{l}0.3 \mathrm{mg} / \mathrm{kg} / \text { twice daily via } \\
\text { subcutaneous injections for one month }\end{array}$ & $\begin{array}{l}\text { oxidative stress, cardiac steatosis and apoptosis } \downarrow \\
\text { AMPK-SIRT1 } \uparrow\end{array}$ & [94] \\
\hline Liraglutide & $\begin{array}{l}\text { Streptozotocin-induced } \\
\text { hyperglycemic apolipoprotein } \\
\text { ApoE-/- mice }\end{array}$ & $\begin{array}{l}17 \mathrm{nmol} / \mathrm{kg} / \text { day or } 107 \mathrm{nmol} / \mathrm{kg} / \text { day } \\
\text { via subcutaneously implanted osmotic } \\
\text { pumps for one month }\end{array}$ & $\begin{array}{l}\text { lipid deposition, plaque volume and intraplaque } \\
\text { macrophage accumulation } \downarrow \\
\text { AMPK-independent } \uparrow\end{array}$ & [55] \\
\hline Liraglutide & ApoE-/-mice & $\begin{array}{l}300 \mathrm{mg} / \mathrm{kg} / \mathrm{twice} \text { daily via s.c injections } \\
\text { for one month }\end{array}$ & $\begin{array}{l}\text { endothelial cell dysfunction } \downarrow \\
\text { eNOS } \uparrow \text { ICAM-1 } \downarrow\end{array}$ & [57] \\
\hline Liraglutide & $\begin{array}{l}\text { ApoE-/- mice with a fat-rich } \\
\text { diet }\end{array}$ & $\begin{array}{l}300 \mu \mathrm{g} / \mathrm{kg} / \text { twice daily via osmotic } \\
\text { mini-pumps for one month }\end{array}$ & $\begin{array}{l}\text { formation } \downarrow \\
\text { progression of atherosclerotic plaque stability } \uparrow \\
\text { GLP-1R-dependent manner }\end{array}$ & [59] \\
\hline Liraglutide & $\begin{array}{l}\text { ApoE-/- male mice with a } \\
\text { high-fat diet }\end{array}$ & $\begin{array}{l}0.4 \mathrm{mg} / \mathrm{kg} / \text { day via subcutaneous } \\
\text { injections for } 9 \text { weeks }\end{array}$ & $\begin{array}{l}\text { atherogenesis } \downarrow \\
\text { AGEs-induced RAGE } \downarrow\end{array}$ & [95] \\
\hline Exenatide & $\begin{array}{l}\text { ApoE-/- mice with a western } \\
\text { diet containing } 21.00 \% \text { fat }\end{array}$ & $\begin{array}{l}300 \mu \mathrm{g} / \mathrm{kg} / \mathrm{twice} \text { daily for } 3 \text { months via } \\
\text { subcutaneous injections }\end{array}$ & $\begin{array}{l}\text { vascular aging and atherosclerotic plaque growth } \downarrow \text {; } \\
\text { APN } \uparrow \text { MMP-9 and MMP-2 } \downarrow \text {; TLR2, TLR4 } \downarrow\end{array}$ & [96] \\
\hline Exenatide & $\begin{array}{l}\text { Female } \mathrm{APOE}^{*} 3 \text {-Leiden.CETP } \\
\text { mice with a western diet }\end{array}$ & $\begin{array}{l}50 \mu \mathrm{g} / \mathrm{kg} / \text { day for one month via an } \\
\text { osmotic minipump }\end{array}$ & $\begin{array}{l}\text { liver inflammation and atherosclerosis development } \downarrow \\
\text { GLP-1 receptor-dependent }\end{array}$ & [63] \\
\hline Exenatide & $\begin{array}{l}\text { Rats with a high-fat diet } \\
\text { containing } 2 \% \text { cholesterol }\end{array}$ & $\begin{array}{l}3 \mu \mathrm{g} / \mathrm{kg} / \text { twice daily via subcutaneous } \\
\text { injection for } 3 \text { and } 6 \text { months }\end{array}$ & $\begin{array}{l}\text { contraction of AGE-induced ECs } \uparrow \\
\text { endothelial barrier injury } \downarrow \\
\text { RAGE/Rho/ROCK } \downarrow ; \text { GLP-1R/cAMP/ PKA } \uparrow\end{array}$ & [97] \\
\hline Exenatide & $\begin{array}{l}\text { Rats with a high-fat diet ( } 2 \% \\
\text { cholesterol) and streptozotocin }\end{array}$ & $\begin{array}{l}3 \mu \mathrm{g} / \mathrm{kg} / \text { twice daily via subcutaneous } \\
\text { injections for } 3 \text { months }\end{array}$ & $\begin{array}{l}\text { endothelial function } \uparrow \text {; aortic oxidative stress level } \downarrow \\
\text { hoA/ROCK/NF-кB/IкBa } \downarrow \text {; AMPK } \uparrow\end{array}$ & [98] \\
\hline Exenatide & C57BL/ 6 or ApoE-/- mice & $\begin{array}{l}\text { low-dose }(300 \mathrm{pmol} / \mathrm{kg} / \text { day }) \text { and } \\
\text { high-dose }(24 \mathrm{nmol} / \mathrm{kg} / \text { day }) \text { for one } \\
\text { month via a mini-osmotic pump }\end{array}$ & $\begin{array}{l}\text { monocytic adhesion } \downarrow \\
\text { TNF a, monocyte chemoattractant protein- } 1 \text {, p65, and } \\
\text { NF-kB } \downarrow\end{array}$ & {$[64]$} \\
\hline Semaglutide & $\begin{array}{l}\text { ApoE-/- and LDLr } /- \text { Mice with } \\
\text { a western diet }\end{array}$ & $\begin{array}{l}\text { 4.0, } 12.0 \text {, or } 60.0 \mathrm{mg} / \mathrm{kg} / \text { day in } \mathrm{ApoE}^{-/-} \\
\text {mice for almost } 3 \text { months or in } \mathrm{LDLr}^{-/-} \\
\text {mice for almost } 4 \text { months }\end{array}$ & $\begin{array}{l}\text { atherosclerosis } \downarrow \\
\text { inflammatory pathways }\end{array}$ & {$[16]$} \\
\hline
\end{tabular}




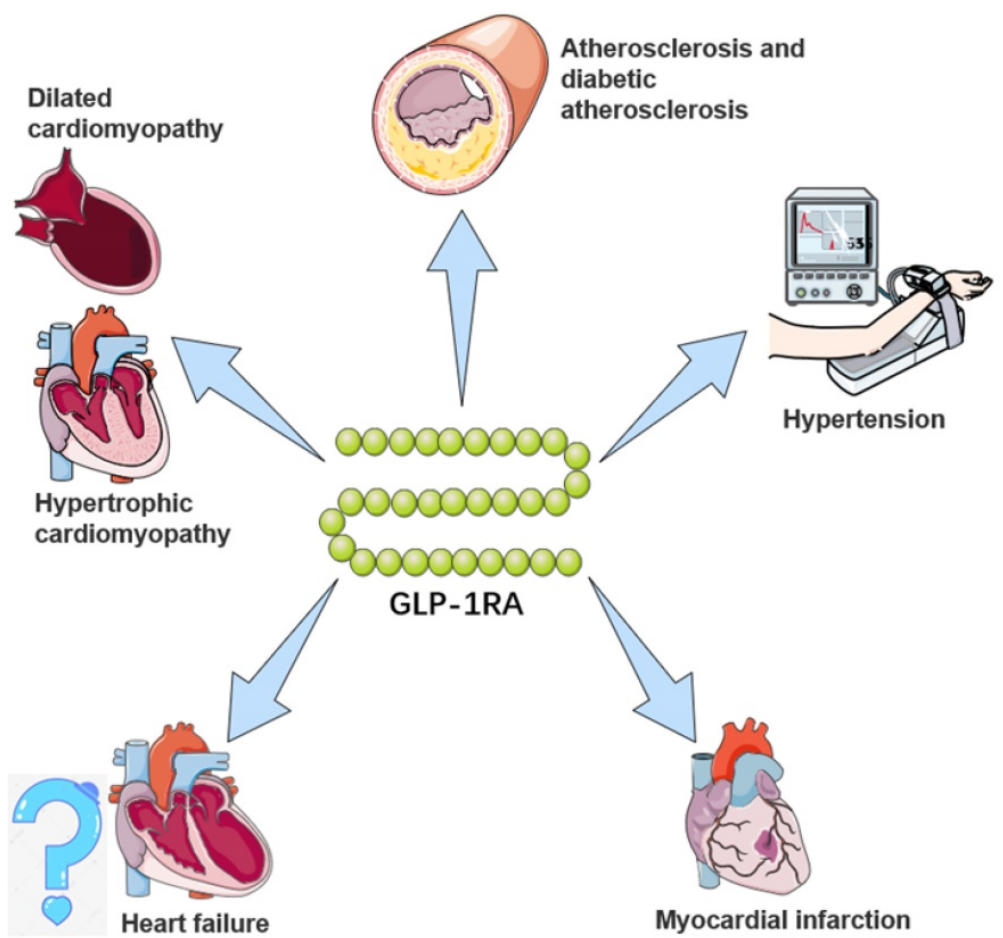

Figure 1. The potential cardiovascular benefits of GLP-1RA. GLP-1RAs have effects on limiting atherosclerosis, controlling hypertension, and delaying the progression of heart failure, myocardial infarction, and cardiomyopathy. For a brief description, GLP-1RAs attenuate and stabilize the development of atherosclerotic plaques through anti-inflammatory mechanisms and preventing vascular remodeling, and inhibit activation and recruitment of macrophages in atherosclerosis. For hypertension, GLP-1RAs augment renal blood flow and promote natriuresis and diuresis. For myocardial infarction, GLP-IRAs alleviate and repair MI via SIRT1/Parkin/mitophagy, insulin-like growth factor-1/2 and upregulating $\alpha$-estrogen receptor. For heart failure, GLP-1RAs remodel calcium circulation disorders, inhibit cardiac hypertrophy by activating the AMPK/mTOR signaling pathway and attenuate methylglyoxal-induced mitochondrial abnormalities. For cardiomyopathy, GLP-1RAs improve mitochondrial function via regulating autophagy and inflammatory signaling, as well as not only mediate the inhibition of myocardial apoptosis, but also improve cardiac energy metabolism.

\section{Effects of GLP-IRAs on cardiomyopathy}

Diabetic cardiomyopathy is an important cardiac complication which is accompanied by cardiac hypertrophy [78]. Chronic inflammation results in the loss of cardiomyocytes in diabetic hearts. GLP-1RAs have the potential to inhibit cardiac inflammation via retarding the production of pyroptotic cytokines, caspase- 1 and the AMPK-thioredoxin interacting protein (TXNIP) pathway in high-fat diet-fed rats [80]. Specifically, GLP-1RAs exert protective effects on exercise-induced cardiomyopathy via increasing autophagy, reducing inflammation-related proteins and ROS generation via restoring the expression of catalase and manganese superoxide dismutase (MnSOD) [81].

GLP-1RAs attenuate apoptosis in cardiomyocytes induced by hyperglycemia via inhibiting receptor of advanced glycation end products (RAGE) receptor [82]. In H9c2 cardiomyoblasts, GLP-1RAs protect against cell apoptosis and inhibit the expression of tumor protein P53 (p53). GLP-1RAs not only mediate the inhibition of myocardial apoptosis, but also improve cardiac energy metabolism. These studies illustrate that GLP-1RAs may confer protective effects on the progression of cardiomyopathy [83].
GLP-1RA treatment also mitigates experimental diabetic cardiomyopathy by the indirect mechanisms of augmenting glucose oxidation in cardiomyocytes [84]. In terms of mechanisms, GLP-1RAs can block C/EBP homologous protein (CHOP)-mediated endoplasmic reticulum (ER) stress via attenuating the irreversible electroporation (IRE)- $\alpha$ unfolded protein response (UPR) [85]. There is a further action that the reduction of HOX transcript antisense RNA (HOTAIR) expression gives rise to cardiomyopathy. As a result, GLP-1RAs demonstrate a new therapeutic action in cirrhotic rats with cardiomyopathy through the protective role of HOTAIR via SIRT1 activation [86].

Abnormal autophagy and mitochondrial injury are involved in diabetic cardiomyopathy. The cardioprotective effects of mesenchymal stem cells, GLP-1RAs or pioglitazone may improve mitochondrial function via regulating autophagy and inflammatory signaling [87]. Several studies revealed that GLP-1RAs relieve myocardial damage and glucose toxicity by promoting autophagy, which is associated with decreasing mTOR phosphorylation and increasing AMPK phosphorylation [88]. Furthermore, a new orally bioavailable GLP-1RA, oral hypoglycemic peptide 2 (OHP2), can confer protective 
effects on diabetic cardiomyopathy through rescuing cardiac lipotoxicity by inhibiting Rho (the small GTPase) kinase (ROCK)/PPARa pathway [89, 90] (Figure 1).

\section{Molecular mechanisms of GLP-1RA- mediated cardiovascular actions}

\section{Lowering blood glucose levels by enhancing insulin secretion}

T2DM is characterized by the presence of chronic fluctuating hyperglycemia, obesity-associated insulin resistance as well as the impaired secretion of insulin and dysfunction of the incretin system. Although endogenous GLP-1 lowers blood glucose levels, it is degraded quickly, which results in loss of its hypoglycemic effects. It follows that long-acting GLP-1RAs have a longer half-life and show prolongation of the glucose-lowering effects [3].

GLP-1RAs can improve $\beta$ cell function in patients with early T2DM via coordinated regulation of the fate of $\alpha$ and $\beta$ cells. There is evidence showing that GLP-1RAs can reduce the expression of $\beta$ cell apoptotic markers Bcl-2-associated $x$ (Bax) and caspase-3 while upregulating Bcl-2 [99, 100], as well as protecting against lipotoxic stress via phosphoinositide 3-kinase (PI3K)/Akt/forkhead box proteins O1 (FoxO1) pathway [101]. GLP-1RAs increase the sensitivity of $\beta$ cells to glucose and positively reduce insulin resistance to further promote insulin secretion [102]. GLP-1RAs stimulate insulin secretion and suppress glucagon secretion, which may modify cardiac energy metabolism in T2DM patients [103]. Based on the above mechanisms of $\beta$ cells, GLP-1RA treatment exerts favorable effects on hyperglycemia (Figure 2).

\section{Reversing endothelial dysfunction by GLP-1RAs}

The cardiovascular phenomenon of endothelial dysfunction involves a series of structural and functional abnormalities, including abnormal secretory capacity and properties of the endothelium and impaired vascular tone, as well as an impaired endothelial barrier function. GLP-1RAs stimulate NO production and eNOS activation, eliciting vasorelaxation in arterial endothelium in vitro [104]. GLP-1RAs make a direct protective impact on the endothelium by the GLP-1R-dependent AMPK/Akt/ eNOS pathway [105]. GLP-1RAs also promote endothelial barrier integrity via activating protein kinase A (PKA)- and Ras-related C3 botulinum toxin substrate 1 (Rac1) [106]. Moreover, GLP-1 exerts stabilizing effects on the endothelial contraction and barrier for AGE-treated endothelium via activating
GLP-1R/cyclic adenosine monophosphate (cAMP)/ PKA and inhibiting mitogen-activated protein kinase (MAPK) signaling pathways together with RAGE/ Rho/ROCK $[97,98]$. Through the above mechanisms, GLP-1RAs can mediate the function of regulating endothelial-mediated contraction and vasodilation, as well as maintaining the stability of the endothelial barrier.

GLP-1RAs can improve the efficacy of protection against the adhesion of inflammatory cells to the endothelium. Specifically, GLP-1RAs downregulate activation of VCAM-1, the intracellular adhesion molecule-1 (ICAM-1) and plasminogen activator inhibitor type 1 (PAI-1) in endothelial cells [57]. Further, GLP-1RAs block the adhesion of monocytes to endothelium induced by oxidized LDL via extracellular signal-regulated kinase (ERK) 5-Kruppel-like factor (KLF)2 signaling pathway to prevent endothelial permeability [107, 108]. Likewise, GLP-RAs inhibit platelet aggregation and prevent thrombosis [109]. These findings indicate that GLP-1RAs have anti-adhesive and anti-thrombotic properties in the endothelium that may delay the development of atherosclerosis [110].

GLP-1RAs play a key role in regulating the response to inflammation of the endothelium. Specifically, GLP-1RAs block NLRP3 (Nod-like receptor protein $3 \mathrm{~h}$ ) inflammasome via SIRT1 activation [111]. GLP-1RAs also suppress the nuclear factor- $\mathrm{kB}$ (NF-kB) pathway and free fatty acid-induced cellular ROS in endothelium [112]. GLP-1RAs also downregulate the expression of MMPs and tissue inhibitors of MPs (TIMPs) for anti-inflammation [110]. Furthermore, noted that GLP-1RAs can increase cholesterol excretion and reduce cholesterol accumulation by promoting the expression of ATP-binding cassette transporter A1 (ABCA1) in the endothelium. Therefore, treatment with GLP-1RAs shows favorable effects on anti-inflammation through the suppression of these proinflammatory cytokine and inflammatory signal pathways, as well as augmenting cholesterol efflux in the endothelium.

GLP-1RAs can exert not only anti-inflammatory effects in the endothelium, but also anti-apoptotic effects aimed at maintaining endothelial homeostasis. GLP-1RAs ameliorate ROS-induced or hyperglycemia-induced apoptosis through modulating IL-6 production and ER stress-induced by hyperhomocysteinemia, via stromal cell-derived factor (SDF)-1 $\beta / \mathrm{C}-\mathrm{X}-\mathrm{C}$ motif receptor 7 (CXCR7) -AMPK/p38-MAPK axis [113-115]. Hereby, the mechanisms of the anti-apoptotic actions involve not only protein kinase cascades, but also the modulation of miRNA levels. Treatment with GLP-1RAs can 
regulate several pivotal miRNAs (such as miR-93-5p, miR-181a-5p and miR-34a-5p and miR-26a-5p) to inhibit apoptosis in endothelium [116]. These findings collectively support the anti-apoptotic actions of GLP-1RAs as part of their effects on endothelial dysfunction.

Under high glucose conditions, endothelial cells acquire the characteristics of fibroblasts, via endothelial-mesenchymal transition (EndMT). EndMT promotes diabetic cardiac fibrosis [117]. EndMT relies on activating the Smad2/3-Slug pathway at an early stage [118]. GLP-1 treatment protects against EndMT through inhibiting the activation of poly (ADP-ribose) polymerase 1 (PARP-1) which can elicit Smad3 and transforming growth factor (TGF)- $\beta 1$ responses. Moreover, GLP-1RAs can reverse EndMT induced by high glucose and IL-1 $\beta$ via activating the AMPK pathway, which was evidenced by augmenting an endothelium marker expression (CD31), as well as alleviating mesenchymal markers expression (SM22a (sensitive $22 \mathrm{kDa}$ actin-binding protein of the calponin), vimentin and Snail) [119]. These results indicate that GLP-1RAs have therapeutic effects against EndMT, an important process in atherosclerosis and fibrotic diseases.

To summarize these mechanisms and their corresponding efficacy with GLP-1RAs or GLP-1, GLP-1RAs show the endothelial protective properties and thus owe to modulating vascular tone and maintaining endothelial barrier integrity, as well as the anti-adhesive and anti-thrombotic actions. In addition, the inhibition of EndMT, the attenuation of inflammation and apoptosis are also responsible for reversing endothelial dysfunction with GLP-1RA treatment (Figure 2).

\section{Improving vascular smooth muscle cell (VSMC) dysfunction by GLP-1RAs}

VSMC dysfunction can be defined as the occurrence of excessive proliferation, autophagy, fibrosis, senescence, and phenotypic transformation. Accordingly, VSMC dysfunction ultimately aggravates vascular injury and accelerates the development of atherosclerosis. GLP-1RAs suppress hyperglycemia-induced proliferation, migration and apoptosis of VSMCs via suppressing the ERK1/2 and PI3K/Akt pathways [10]. In terms of proliferation, liraglutide attenuates VSMC proliferation induced by Ang II through eliciting cell cycle arrest and activating AMPK [120]. Furthermore, the number of neuron-derived orphan receptor 1 (NOR1) which can modulate VSMC proliferation, is decreased by GLP-1RAs in a dose-dependent manner in mice [121].

VSMC senescence induced by Ang II is another important aspect of VSMC dysfunction. In this regard, GLP-1RAs can provide the protection against VSMC senescence via increasing the nuclear factor erythroid 2-related factor 2 (Nrf2) activity [122]. In addition, GLP-1RAs inhibit superoxide anion formation and ensuing VSMC senescence through suppressing Rac1 activation via cAMP/PKA pathways [123].

VSMC phenotypic switching is characterized by transformation from a quiescent contractile to an activated synthetic phenotype, promoting proliferation and leading to the formation of the neointima, the pathological vascular compartment critical for the development of atherosclerosis. In rat coronary artery smooth muscle cells, GLP-1RAs can inhibit phenotypic modulation induced by AGEs through blocking the NF-kB signaling pathway [124]. Further, GLP-1RAs promote VSMC redifferentiation via AMPK/SIRT1/forkhead box $\mathrm{O}$ (FOXO3a) pathways, where the expression of contractile VSMCs markers (SM22a and Calponin) is increased [125]. Likewise, GLP-1 inhibits VSMC dedifferentiation by regulating mitochondrial dynamics via enhancing adiponectin (APN) expression, which in turn promotes the phosphorylation of AMPK and SIRT1 in VSMC [126, 127].

Osteoblastic differentiation of VSMCs plays an important cytopathological role in arterial calcification. By inhibiting osteoblast differentiation of VSMCs, GLP-1RAs can ameliorate phosphateinduced vascular calcification, which is mediated by the AMPK/mTOR pathway or AMPK/receptor activator of nuclear factor kappa B ligand (RANKL), as occurs in the osteoblast differentiation of VSMCs $[128,129]$.

Arterial restenosis and vascular remodeling are a response to vascular injury, usually manifested as neointimal hyperplasia. GLP-1RAs can inhibit neointimal hyperplasia by suppressing VSMC proliferation and migration as mentioned above. GLP-1 treatment can exert the direct action on reversing vascular remodeling by downregulating MMP1 expression via alleviating the ERK1/2/NF-kB pathway in Ang II-induced rat aortic VSMCs [130]. Furthermore, GLP-1R activation can prevent arterial restenosis through inhibiting VSMC proliferation and migration via stress-associated endoplasmic reticulum protein 1 (SERP1) [131].

As a result, GL-1RAs play a role in reversing or improving VSMC dysfunction by suppressing VSMCs proliferation, migration, apoptosis, as well as inhibiting VSMC phenotypic switching, especially inhibiting osteoblastic differentiation. GLP-1RAs have an impact in reversing vascular remodeling and attenuating the progression of VSMC senescence (Figure 2). 


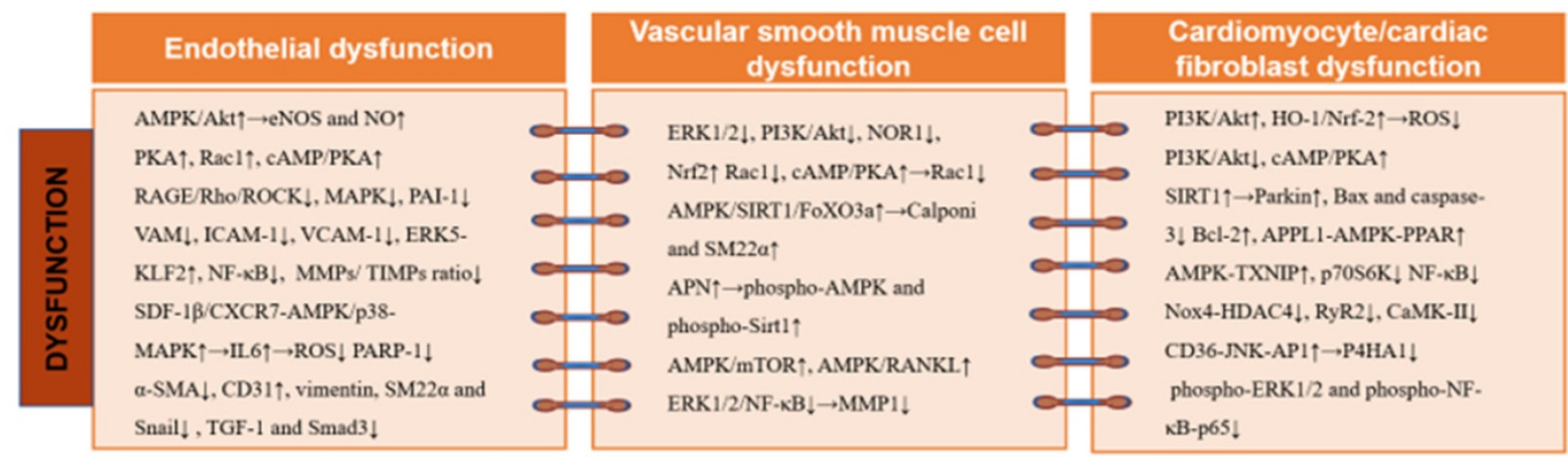

\section{Macrophage inflammation, foam cell formation, and polarization \\ NLRP3 inflammasome inhibition}

Immune cell function and inflammation
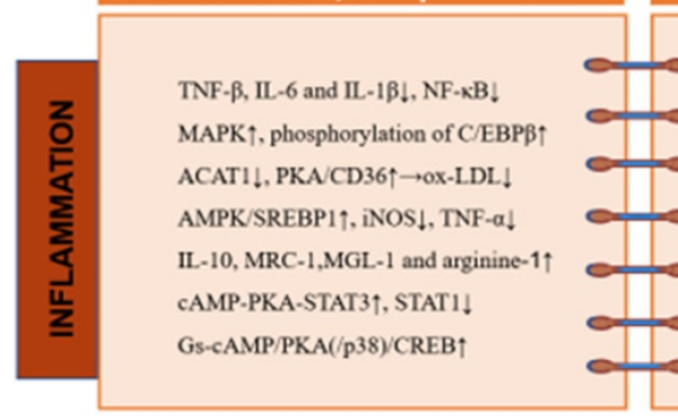

Reducing blood glucose levels

NLRP3 $\downarrow, A S C \downarrow, P 10 \downarrow$

SIRT $1 \uparrow / N O X 4 \downarrow \rightarrow$ TNF- $\alpha$

ROS $\downarrow$, IL-10†

3-methyladenine/PINK $1 \uparrow$

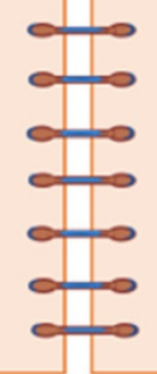

IL-2\, IFN- $\gamma \downarrow$, miR-19b!

CRP $\downarrow$, JAK-STAT $\downarrow \rightarrow$ IFN $-\gamma \downarrow$

CTL Treg ratio $\uparrow$, iNKT cell $\uparrow$

- increases the sensitivity of $\beta$

cells to glucose

- Reduces insulin resistance

- improve $\beta$ cell function

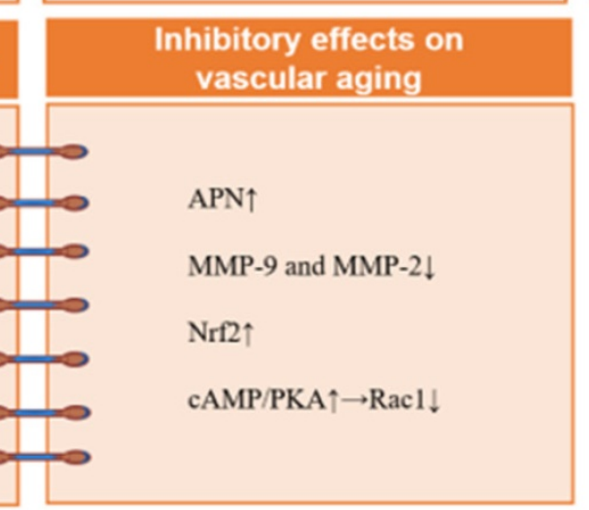

Figure 2. The cardiovascular protective effects of GLP-1RA involve multiple molecular mechanisms and signaling pathways. GLP-1RA inhibit endothelial cell dysfunction while attenuating abnormal migration, proliferation, and apoptosis in VSMCs. In addition, GLP-1RA decrease macrophage inflammation and blocks NLRP3 inflammasome activation. Further, GLP-1RA protect against vascular aging and maintains the metabolic homeostasis of cardiomyocytes. Abbreviations: ACAT: acyl-CoA cholesterol acyltransferase; AMPK: AMP-activated protein kinase; APN: adiponectin; APPL: activating the leucine zipper motif; ASC: apoptotic speck containing protein; Bax: Bcl-2-associated x; Bcl: B-cell lymphoma; CaMK: calmodulin-dependent protein kinase; cAMP: cyclic adenosine monophosphate; CD31: cell adhesion molecule; C/EBP $\beta$ : CCAAT/enhancer-binding protein $\beta$; CREB: CAMP response element binding-protein; CRP: C-reactive protein; CTL: cytotoxic T lymphocyte; CXCR: C-X-C motif receptor; eNOS: endothelial NO synthase; ERK: extracellular signal-regulated kinase; FOXO: forkhead box O; HDAC4: histone deacetylase 4; HO-1: heme oxygenase-1; ICAM-1: intracellular adhesion molecule-1; IFN: interferon; IL: interleukin; iNKT: invariant natural killer T; iNOS: inducible NOS; JAK: Janus kinase; JNL: Jun NH2-terminal kinase; KLF2: Kruppel-like factor 2; MAPK: mitogen-activated protein kinases; MGL-1: macrophage galectin-1; MMP: matrix metalloproteinase; MRC-1: mannose receptor-1; mTOR: mechanistic target of rapamycin; NF-KB: a nuclear factor-KB; NLRP3: Nod-like receptor protein 3; NOR1: neuron-derived orphan receptor 1; Nox4: NADPH oxidase 4; Nrf2: nuclear factor erythroid 2-related factor 2; ox-LDL: oxidized-LDL; PAI: plasminogen activator inhibitor; PARP-1: poly(ADP-ribose) polymerase 1; PINK1: the mitochondrial kinase; PI3K: phosphoinositide 3-kinase; PKA: protein kinase A; PPAR: peroxisome proliferator-activated receptor; P10: cleaved caspase 1; P4HA1: prolyl 4-hydroxylase subunit alpha-1; p70S6K: p70 ribosomal protein S6 kinase; Rac1: Ras-related C3 botulinum toxin substrate 1; RAGE: receptor AGE; RANKL: receptor activator of nuclear factor kappa B ligand; Rho: the small GTPase; ROCK: Rho kinase; ROS: reactive oxygen species; RyR2: the type 2 ryanodine receptor; SDF: stromal cell-derived factor; SREBP1: element binding transcription factor 1; SIRT: sirtulin; a-SMA: alpha smooth muscle actin; SM22a: sensitive 22 kDa actin-binding protein of the calponin; STAT: cAMP-PKA-signal transducers and activators of transcription; TGF: transforming growth factor; TIMP: tissue inhibitor of MPs; TNF: tumor necrosis factor; Treg: regulatory T cell; TXNIP: AMPK-Thioredoxin-interacting protein; VAM: vascular adhesion molecule; VCAM-1: vascular cell adhesion molecule 1; VSMC: vascular smooth muscle cells.

\section{Reducing macrophage inflammation, foam cell formation, and polarization by GLP-1RAs}

Under pathological stress, macrophages contribute to inflammatory responses, which drive insulin resistance and T2DM. In this regard, GLP-1RAs (exendin-4, for example) not only alleviate macrophage infiltration, but also suppress IL-1 $\beta$, IL-6 and TNF- $\alpha$ expression. Mechanistically, in macrophages, GLP-1RAs directly ameliorate NF-KB activation, thereby improving insulin resistance [132]. In addition, GLP-1RAs and metformin can suppress pro-inflammatory phenotypes of monocyte/ macrophages through impacts on the CCAAT/ 
enhancer-binding protein beta (C/EBP $\beta)$, together with MAPK and NF-kB [133]. As a result, GLP-1RAs can inhibit macrophage-associated inflammation through the above mechanisms.

The transformation of monocyte/macrophages into foam cells, is the hallmark of atherogenesis. Vascular located monocytes/macrophages engulf oxidized-LDL (ox-LDL), generating foam cells which release a plethora of pro-inflammatory mediators. The process of foam cell formation occurs via the imbalanced influx and efflux of modified lipoproteins. After lipid uptake, acyl-CoA: cholesterol acyltransferase 1 (ACAT1) catalyzes cholesterol esterification. GLP-1RAs can suppress foam cell formation by activating GLP-1R signaling induced autophagy [134], reducing ACAT1 expression/ activity [93], as well as inhibiting the PKA/CD36 pathway to inhibit ox-LDL uptake [135]. Although in foam cells, GLP-1RAs also can protect against oxidative stress and steatosis via modulation of AMPK/sterol regulatory element binding transcription factor 1 (SREBP1) [136]. Therefore, the reduction of foam cells with GLP-1RAs treatment is speculated to inhibit vascular senescence and delay the progression of atherosclerosis.

The activation of macrophages by GLP-1 also contributes to anti-inflammatory factor secretion and M2 polarization. In this regard, GLP-1 treatment leads to decreased expression of macrophage-specific markers for M1 (inducible NOS (iNOS), IL-6 and TNF-a) and enhances expression level of M2-marker genes, including arginine-1, macrophage galectin-1 (MGL-1), IL-10, as well as mannose receptor-1 (MRC-1). Mechanistic evidence has indicated that GLP-1RAs promote bone marrow-derived macrophage polarization into the M2 phenotype via the cAMP-PKA-signal transducers and activators of the transcription 3 (STAT3) pathway [137, 138]. It is acknowledged that activation of STAT3 which is crucial to M2 phenotype transformation, while STAT1 activity which is a key determinant for the M1 subtype. Hereby, GLP-1RAs can diminish STAT1 activity [91]. By modulating macrophage polarization towards an M2 subtype, GLP-1RAs can inhibit inflammation occurring in the vessel lumen, an action which would alleviate the progression of atherosclerosis (Figure 2).

\section{Inhibition of NLRP3 inflammasome by GLP-1RAs}

NLRP3 inflammasome activation induced by hyperglycemia can cause endothelial dysfunction in T2DM. GLP-1RAs suppress NLRP3 inflammasome activation via attenuating the expression of NLRP3, apoptotic speck containing protein (ASC), and cleaves caspase 1 (p10) [111]. Besides, in H9c2 cardiomyocytes, GLP-1RAs also inhibit hypoxiainduced NLRP3 inflammasome activity and TNF-a to attenuate pyroptosis through modulating the SIRT1/ NADPH oxidase 4 (NOX4)/ROS pathway [139]. Whereas, the suppression of NLRP3 can be functioned by GLP-1RAs not only directly but also indirectly.

In addition, the inhibition of NLRP3 activation by GLP-1RAs requires regulation of the mitochondrial pathway. GLP-1RAs augment the mitophagy pathway to suppress NLRP3 inflammasome and ameliorate oxidative stress-induced injury in the liver [140]. Hereby, the suppression of inflammatory injury with GLP-1RAs treatment can be eliminated by 3-methyladenine/the mitochondrial kinase (PINK1) siRNA [141]. Moreover, what is clinically noteworthy, is that GLP-1RA treatment can reduce intimal hyperplasia after stent implantation by modulating the above pathway [142]. Combined with abovementioned data, GLP-1RAs show a positive impact on the suppression of NLRP3 inflammasome (Figure 2).

\section{Modulating immune cell function and inflammation by GLP-1RAs}

The development of diabetes and obesity is underpinned by chronic inflammation [143]. In this context, GLP-1RAs can inhibit the secretion of IL-2 and interferon (IFN)- $\gamma$, thereby regulating the immune microenvironment and preventing diabetes [144]. GLP-1RA can inhibit the progression of atherosclerosis in the early phase by regulation of immune cell phenotypes. Particularly, liraglutide attenuates pre-established atherosclerosis throughout the aorta and aortic root in $\mathrm{ApoE}^{-/}$mice via increasing macrophage polarization into anti-inflammatory macrophages and by reducing the number of pro-inflammatory macrophages [92]. By doing so, in atherosclerotic plaques from murine aortas, GLP-1RAs regulate proinflammatory mediators and the phenotype of immune cells.

The immuno-modulatory effects of GLP-1RAs also suggest their potential in T1DM. In non-obese diabetic (NOD) mice which are a murine model of T1DM, GLP-1RAs can improve immune functions and inflammatory responses as well as mitigating against islet cell damage, an action which may be related to the decrease in the expression of miR-19b [145]. Similarly, GLP-1RAs exert the potential protection against inflammatory responses in T1DM through decreasing IFN- $\gamma$ secretion and downregulating PD-1 expression in $\mathrm{T}$ cells by attenuating the Janus kinase (JAK)-STAT pathway $[146,147]$. Thus, GLP-1RAs play an underlying role in immune-regulation in T1DM (Figure 2). 


\section{Inhibitory effects on vascular aging by GLP-1RAs}

Aging is a crucial component of the pathogenesis of CVD, as reflected by increased oxidative stress and impaired antioxidant defense, responses which may be induced by psychosocial stress [122, 148]. ROS and inflammation are main mediators of vascular senescence. GLP-1RAs alleviate vascular aging under chronic stress via increasing adiponectin (APN) levels and inhibiting aortic MMP-9 and MMP-2 expression in $\mathrm{ApoE}^{-/-}$mice [96, 149]. Excessive autophagy is another cause of vascular aging. GLP-1 treatment can attenuate abnormal autophagy induced by ROS and inflammation through upregulating HDAC6 via the GLP-1R-ERK1/2 pathway [150]. ER stress and DNA damage are also responsible for vascular senescence. Regarding this, GLP-1RAs inhibit ER stress and promote protein folding via endoplasmic reticulum oxidoreductase (ERO1a) in an AMPK-dependent manner, as well as mediating the process of mitochondrial fusion [115, 151]. For senescence of VSMCs, GLP-1RAs activate Nrf2 and inhibit Rac1 through cAMP/PKA pathways to prevent Ag II-induced senescence [122, 123]. In brief, all of the mechanisms and actions that have protective efficiency on endothelium and VSMCs, can play a role in preventing vascular senescence (Figure 2).

\section{Improving cardiomyocyte/cardiac fibroblast dysfunction by GLP-1RAs}

Cardiomyocyte/cardiac fibroblast dysfunction is related to abnormal proliferation, apoptosis, hypertrophy, as well as inflammation and fibrosis, which may be caused by mitochondrial dysfunction and metabolic disorders. Persistent hyperglycemia can mediate hypoxic or ischemic injury, as well as elicit cardiomyocyte contractile dysfunction and the NF- $\mathrm{KB}$ signaling pathway activation, thus inducing ER stress [152]. GLP-1RA can help maintain a balance of energy metabolism in cardiomyocytes through activating PI3K/Akt as well as p38 MAPK pathways as well as activating Nrf-2/heme oxygenase-1 (HO-1), contributing to augmented adenosine triphosphate formation and glucose ingestion by cardiomyocytes [153-155]. Based on these pathways, GLP-1RAs improve metabolic disorders to alleviate cardiomyocyte dysfunction.

Apoptosis of cardiomyocytes is usually irreversible, leading to myocardial damage. GLP-1RAs make an impact on anti-apoptosis through multiple pathways. Firstly, the impact is partly due to ameliorating caspase-3 and Bax activity and upregulating Bcl-2 [156]. Secondly, GLP-1RAs attenuate apoptosis induced by TNF-a by ameliorating mitochondrial dysfunction related to activating the GLP-1R/cAMP/PKA and AMPK/ SIRT1 pathway [94, 157, 158]. Thirdly, GLP-1RAs exert anti-apoptotic actions attributable to the activation of Notch signaling [159]. Fourthly, GLP-1 protects cardiomyocytes from oxidative stress and apoptosis in diabetes mellitus, through the mTOR complex1/p70 ribosomal protein S6 kinase (p70S6K) pathway [160]. Fifth, GLP-1RAs protect against cardiomyocyte apoptosis under diabetic conditions via activating the leucine zipper motif (APPL $L_{1}$ AMPK-PPARa axis and the AMPK-TXNIP pathway [80, 161].

Cardiac inflammation, fibrosis and hypertrophy are the main manifestations of myocardial dysfunction. Hyperglycemia-mediated cardiomyocyte damage is associated with inflammation. GLP-1RAs can have effects on inflammation and defending ER stress via suppressing NF-KB in diabetic cardiomyocyte models [152]. GLP-1R can also suppress cardiac hypertrophy induced by Ang II through attenuating the Nox4-histone deacetylase 4 (HDAC4) axis [162]. Apart from these actions, GLP-1RAs ameliorate cardiac fibrosis induced by abdominal aortic constriction via interfering with Ang II type 1 receptor signaling [163]. Therefore, GLP-1RAs can provide protective effects on the above undesirable physiological phenomena in cardiomyocytes.

GLP-1RAs can modulate intracellular calcium homeostasis to prevent reperfusion injury directly in cardiomyocytes [164]. GLP-1RAs also exert anti-arrhythmic effects via reducing calcium leak from the sarcoplasmic reticulum in ventricular arrhythmia, which has the potential to decrease phosphorylation of the type 2 ryanodine receptor (RyR2) and alleviate the activity of CaMK-II [77]. Moreover, GLP-1R activation counteracts the effects of $\beta$-adrenoceptor stimulation on cardiac ventricular excitability and reduces ventricular arrhythmic potential [165]. Apart from maintaining calcium channel homeostasis, GLP-1RAs also activate ATPsensitive potassium channels to attenuate cardiac apoptosis and hypertrophy induced by pressure overload [166].

In addition to regulating cardiomyocyte function, GLP-1RAs also improve the function of cardiac fibroblasts. For example, GLP-1RAs may modulate the CD36-JNK-AP1 pathway by partially down-regulating prolyl 4-hydroxylase subunit alpha-1 (P4HA1), and then inhibit ROS production mediated by Ang II type I receptor, thereby ameliorating cardiac fibroblast proliferation and myocardial fibrosis $[167,168]$. Furthermore, as for cardiac fibroblasts, GLP-1RAs inhibit Ang II and glucose-induced collagen formation via decreasing 
phospho-NF-kB-p65 and phospho-ERK1/2 expression [169] (Figure 2).

To sum up, GLP-1RAs improve cardiomyocyte/ cardiac fibroblast dysfunction by making balancing energy metabolism, and multiple pathways related to AMPK to inhibit cardiac apoptosis. Moreover, the suppression of cardiac inflammation, fibrosis and hypertrophy with GLP-1RA treatment provide a clinically favorable impact on cardiac dysfunction.

\section{Discussion}

\section{Heterogeneous effects of GLP-1RAs in CVOTs}

In the GLP-1RA family of agents, the results of CVOT have been inconsistent. The baseline characteristics of the study populations, study drugs and study designs may be considered as possible reasons for the variability [170]. Furthermore, a real-world retrospective study comparing the compliance of patients receiving different GLP-1RAs for the treatment of hyperglycemic found that even if GLP-1RA weekly preparations were used, there were still differences in compliance [171]. Such differences in compliance between GLP-1RA preparations are mainly due to the differences between injection devices [172]. Ultimately, the duration of GLP-1RA treatment seems to be the factor that explains the heterogeneity of the clinical studies involving GLP-1RA.

Although some promising observations have been reported in various animal models, the impact of GLP-1RAs on human myocardial function is more heterogeneous. In a randomized controlled study, exenatide administered once a week for 18 months did not change carotid plaque volume or composition [173]. Further, while GLP-1RAs have a positive impact on the LVEF, it seems to be inconsistent in most patients with heart failure and effects are quite limited [174]. However, it is currently unclear and to what extent the differences observed in CVOT reflect the heterogeneous pharmacological properties of each drug in the GLP-1RA category. In order to enhance the clinical interpretation of these CVOTs, researchers have quantified the absolute treatment effect over time based on the number of treatments required to avoid a MACE, thus revealed the difference between GLP-1RA [175]. Also, due to the important role of endothelial dysfunction in CVD, the effects of GLP-1RA on flow-mediated vasodilation (FMD) in patients remain to be investigated for their contribution to the CVD actions of GLP-1RAs.

\section{New pharmacological effects and molecular targets of GLP-1 RAs}

Our understanding of the disease mechanisms and molecular targets of drugs has been facilitated by new biotechnology advances, such as RNA sequencing. RNA-seq can also be used as a useful tool to dissect the molecular targets of drugs in CVD [176]. Therefore, the use of new technological advances such as single cell RNA-seq can shed new light on the GLP-1RA-dependent and independent effects and targets in animal models and humans [177].

\section{The theranostic potential of new modifiers of GLP-1RAs}

Due to the high expression profile of GLP-1R in pancreatic $\beta$-cells, GLP-1 analogs (such as exendin-4) have been modified by different methods (to prolong half-life, maintain receptor binding affinity and reduce renal drug accumulation) for theranostic purposes and serve as excellent templates for future cardiovascular drug development[178-184]. More importantly, these modified GLP-1 analogues have shown hypoglycemic [185, 186] and cardiovascular protective effects [180, 183] in different animal models. Further exploration of these modified agents in animal models of cardiometabolic diseases will deepen our understanding of the potential cardioprotective mechanisms of GLP-1 and GLP-1RAs and potentially provide future directions for precise therapeutic intervention [180].

GLP-1RAs are a class of agents with pleiotropic activities additional to the lowering of blood glucose. These pleiotropic effects include the reduction of BW and $\mathrm{BP}$, the improvement of lipid metabolism and a spectrum of cardioprotective effects. The current comprehensive management strategy of diabetes has gradually shifted from "hypoglycemic as the focus" to "emphasizing both the control of blood glucose and the improvement of MACE and cardiovascular outcomes" [187, 188]. In this regard, GLP-1RAs have shown promising efficacy as to the improvement of hard cardiovascular outcomes with cardiovascular safety.

\section{Conclusions}

The ADA standard for the treatment of diabetes updated in 2020 indicated that patients with T2DM diagnosed with CVD or those with CVD risk factors can use GLP-1RAs and SGLT2 inhibitors with evidence of cardiovascular benefits to reduce cardiovascular risk, regardless of $\mathrm{HbA1c}$ levels or individualized HbA1c control objectives [189]. This guideline emphasizes the importance of the primary and secondary prevention of CVD with both GLP-1RAs and SGLT2 inhibitors. It remains to be investigated whether cardiovascular protective effects of GLP-1RAs can also be independent of the known effects on glucose metabolism. In the future, more 
GLP-1RAs will be explored for the improvement of ischemic stroke and cognitive impairment in patients with diabetes [190]. More importantly, endocrinologists should work coordinately with cardiologists and pharmacologists to establish GLP-1RA-dependent and independent effects in preparation for precisely commencing therapy with GLP-1RAs in suitable targeted patient categories.

\section{Abbreviations}

ABCA1: ATP-binding cassette transporter A1; ACAT: acyl-CoA cholesterol acyltransferase; AMPK: AMP-activated protein kinase; APN: adiponectin; ApoE-/: apolipoprotein E-deficient; APPL: activating the leucine zipper motif; ASC: apoptotic speck containing protein; Bax: Bcl-2-associated $\mathrm{x}$; Bcl: B-cell lymphoma; BP: body pressure; BW: body weight; CaMK: calmodulin-dependent protein kinase; cAMP: cyclic adenosine monophosphate; CD31: cell adhesion molecule; C/EBP $\beta$ : CCAAT/enhancer-binding protein $\beta$; CREB: CAMP response element binding-protein; CKD: chronic kidney disease; CRP: C-reactive protein; CTL: cytotoxic T lymphocyte; CVD: cardiovascular diseases; CVOT: cardiovascular outcomes trials; CXCR: C-X-C motif receptor; eNOS: endothelial NO synthase; ERK: extracellular signal-regulated kinase; FOXO: forkhead box $\mathrm{O}$; GLP-1RA: receptor agonists for hormone glucagon like peptide-1; HDAC4: histone deacetylase 4; HO-1: heme oxygenase-1; ICAM-1: intracellular adhesion molecule-1; IFN: interferon; IL: interleukin; iNKT: invariant natural killer T; iNOS: inducible NOS; JAK: Janus kinase; JNL: Jun NH2-terminal kinase; KLF2: Kruppel-like factor 2; $\mathrm{LDLr}^{-/-:}$low-density lipoprotein receptor-deficient; MACE: major cardiovascular events; MAPK: mitogen-activated protein kinases; MGL-1: macrophage galectin-1; MI: myocardial infarction; MMP: matrix metalloproteinase; MRC-1: mannose receptor-1; mTOR: mechanistic target of rapamycin; NF-kB: nuclear factor-kB; NLRP3: Nod-like receptor protein 3; NOR1: neuron-derived orphan receptor 1; Nox4: NADPH oxidase 4; Nrf2: nuclear factor erythroid 2-related factor 2; ox-LDL: oxidized-LDL; PAI: plasminogen activator inhibitor; PARP-1: poly(ADP-ribose) polymerase 1; PINK1: the mitochondrial kinase; PI3K: phosphoinositide 3-kinase; PKA: protein kinase A; PPAR: peroxisome proliferator-activated receptor; P10: cleaved caspase 1; P4HA1: prolyl 4-hydroxylase subunit alpha-1; p70S6K: p70 ribosomal protein S6 kinase; Rac1: Ras-related C3 botulinum toxin substrate 1; RAGE: receptor AGE; RANKL: receptor activator of nuclear factor kappa B ligand; Rho: the small GTPase; ROCK: Rho kinase; ROS: reactive oxygen species; RyR2: the type 2 ryanodine receptor; SDF: stromal cell-derived factor; SREBP1: element binding transcription factor 1; SIRT: sirtulin; a-SMA: alpha smooth muscle actin; SM22a: sensitive $22 \mathrm{kDa}$ actin-binding protein of the calponin; STAT: cAMP-PKA-signal transducers and activators of transcription; TGF: transforming growth factor; TIMP: tissue inhibitor of MMPs; TNF: tumor necrosis factor; Treg: regulatory $\mathrm{T}$ cell; $\mathrm{TXNIP}$ : thioredoxin-interacting protein; T2DM: type 2 diabetes mellitus; VAM: vascular adhesion molecule; VCAM-1: vascular cell adhesion molecule 1; VSMC: vascular smooth muscle cells.

\section{Acknowledgements}

This study was supported by grants from National Natural Science Foundation of China [Grant Nos. 82070464 to SX, 81941022 to JW, 81530025 to JW], Strategic Priority Research Program of Chinese Academy of Sciences [Grant No. XDB38010100 to JW] and the National Key R\&D Program of China [Grant No. 2017YFC1309603 to JW]. This work was also supported by Key R\&D Program of Anhui Province (to SX), Program for Innovative Research Team of The First Affiliated Hospital of USTC (to JW), Local Innovative and Research Teams Project of Guangdong Pearl River Talents Program [2017BT01S131], China International Medical Foundation (to XZ), Natural Science Foundation of Anhui Province [Grant No. 006223066002 to SL] as well as a special fund from Hefei Comprehensive National Science Center.

\section{Competing Interests}

The authors have declared that no competing interest exists.

\section{References}

1. Barquera S, Pedroza-Tobías A, Medina C, Hernández-Barrera L, Bibbins-Domingo K, Lozano R, Moran AE: Global Overview of the Epidemiology of Atherosclerotic Cardiovascular Disease. Archives of medical research. 2015; 46(5):328-338.

2. Cardiovascular Disease and Risk Management: Standards of Medical Care in Diabetes-2018. Diabetes care. 2018; 41(Suppl 1):S86-s104.

3. Heuvelman VD, Van Raalte DH, Smits MM: Cardiovascular effects of glucagon-like peptide 1 receptor agonists: from mechanistic studies in humans to clinical outcomes. Cardiovascular research. 2020; 116(5):916-930.

4. Marso SP, Daniels GH, Brown-Frandsen K, Kristensen P, Mann JF, Nauck MA, Nissen SE, Pocock S, Poulter NR, Ravn LS et al: Liraglutide and Cardiovascular Outcomes in Type 2 Diabetes. The New England journal of medicine. 2016; 375(4):311-322.

5. Yamagishi S, Matsui T: Pleiotropic effects of glucagon-like peptide-1 (GLP-1)-based therapies on vascular complications in diabetes. Current pharmaceutical design. 2011; 17(38):4379-4385.

6. Meier JJ, Gethmann A, Götze O, Gallwitz B, Holst JJ, Schmidt WE, Nauck MA: Glucagon-like peptide 1 abolishes the postprandial rise in triglyceride concentrations and lowers levels of non-esterified fatty acids in humans. Diabetologia. 2006; 49(3):452-458

7. Zander M, Madsbad S, Madsen JL, Holst JJ: Effect of 6-week course of glucagon-like peptide 1 on glycaemic control, insulin sensitivity, and beta-cell function in type 2 diabetes: a parallel-group study. Lancet (London, England). 2002; 359(9309):824-830.

8. McCormick LM, Kydd AC, Dutka DP: Cardiac protection via metabolic modulation: an emerging role for incretin-based therapies? Cardiovascular $\mathcal{E}$ hematological agents in medicinal chemistry. 2012; 10(4):319-324.

9. Sélley E, Kun S, Szijártó IA, Kertész M, Wittmann I, Molnár GA: Vasodilator Effect of Glucagon: Receptorial Crosstalk Among Glucagon, GLP-1, and Receptor for Glucagon and GLP-1. Hormone and metabolic research $=$ Hormonund Stoffwechselforschung $=$ Hormones et metabolism. 2016; 48(7):476-483. 
10. Shi L, Ji Y, Jiang X, Zhou L, Xu Y, Li Y, Jiang W, Meng P, Liu X: Liraglutide attenuates high glucose-induced abnormal cell migration, proliferation, and apoptosis of vascular smooth muscle cells by activating the GLP-1 receptor, and inhibiting ERK1/2 and PI3K/Akt signaling pathways. Cardiovascular diabetology. 2015; 14:18

11. Gentilella R, Pechtner V, Corcos A, Consoli A: Glucagon-like peptide-1 receptor agonists in type 2 diabetes treatment: are they all the same? Diabetes/metabolism research and reviews. 2019; 35(1):e3070.

12. Eid RA, Khalil MA, Alkhateeb MA, Eleawa SM, Zaki MSA, El-Kott AF, Al-Shraim M, El-Sayed F, Eldeen MA, Bin-Meferij MM et al: Exendin-4 Attenuates Remodeling in the Remote Myocardium of Rats After an Acute Myocardial Infarction by Activating $\beta$-Arrestin-2, Protein Phosphatase 2A, and Glycogen Synthase Kinase-3 and Inhibiting $\beta$-Catenin. Cardiovascular drugs and therapy. 2020

13. Eid RA, Zaki MSA, Alaa Eldeen M, Alshehri MM, Shati AA, El-Kott AF: Exendin- 4 protects the hearts of rats from ischaemia/reperfusion injury by boosting antioxidant levels and inhibition of JNK/p(66) Shc/NADPH axis. Clinical and experimental pharmacology \& physiology. 2020; 47(7):1240-1253.

14. Blonde L, Berard L, Saremi A, Huang Y, Aroda VR, Raccah D: Fixed-Ratio Combination of Insulin and GLP-1 RA in Patients with Longstanding Type 2 Diabetes: A Subanalysis of LixiLan-L. Diabetes therapy : research, treatment and education of diabetes and related disorders. 2020; 11(4):1007-1015.

15. Helmstädter J, Frenis K, Filippou K, Grill A, Dib M, Kalinovic S, Pawelke F, Kus K, Kröller-Schön S, Oelze M et al: Endothelial GLP-1 (Glucagon-Like Peptide-1) Receptor Mediates Cardiovascular Protection by Liraglutide In Mice With Experimental Arterial Hypertension. Arteriosclerosis, thrombosis, and vascular biology. 2020; 40(1):145-158.

16. Rakipovski G, Rolin B, Nøhr J, Klewe I, Frederiksen KS, Augustin R, Hecksher-Sørensen J, Ingvorsen C, Polex-Wolf J, Knudsen LB: The GLP-1 Analogs Liraglutide and Semaglutide Reduce Atherosclerosis in ApoE(-/-) and LDLr(-/-) Mice by a Mechanism That Includes Inflammatory Pathways. JACC Basic to translational science .2018; 3(6):844-857.

17. Avgerinos I, Michailidis T, Liakos A, Karagiannis T, Matthews DR, Tsapas A, Bekiari E: Oral semaglutide for type 2 diabetes: A systematic review and meta-analysis. Diabetes, obesity \& metabolism 2020, 22(3):335-345.

18. Xu F, Cao H, Chen Z, Gu H, Guo W, Lin B, Weng J: Short-term GLP-1 receptor agonist exenatide ameliorates intramyocellular lipid deposition without weight loss in ob/ob mice. International journal of obesity (2005). 2020; 44(4):937-947.

19. Htike ZZ, Zaccardi F, Papamargaritis D, Webb DR, Khunti K, Davies MJ: Efficacy and safety of glucagon-like peptide-1 receptor agonists in type 2 diabetes: A systematic review and mixed-treatment comparison analysis. Diabetes, obesity \& metabolism. 2017; 19(4):524-536.

20. Uhles S, Wang H, Bénardeau A, Prummer M, Brecheisen M, Sewing S, Tobalina L, Bosco D, Wollheim CB, Migliorini C et al: Taspoglutide, a novel human once-weekly GLP-1 analogue, protects pancreatic $\beta$-cells in vitro and preserves islet structure and function in the Zucker diabetic fatty rat in vivo. Diabetes, obesity \& metabolism. 2011; 13(4):326-336.

21. Pratley R, Amod A, Hoff ST, Kadowaki T, Lingvay I, Nauck M, Pedersen KB, Saugstrup T, Meier JJ: Oral semaglutide versus subcutaneous liraglutide and placebo in type 2 diabetes (PIONEER 4): a randomised, double-blind, phase 3a trial. Lancet (London, England. 2019; 394(10192):39-50.

22. Marso SP, Bain SC, Consoli A, Eliaschewitz FG, Jódar E, Leiter LA, Lingvay I, Rosenstock J, Seufert J, Warren ML et al: Semaglutide and Cardiovascular Outcomes in Patients with Type 2 Diabetes. The New England journal of medicine. 2016; 375(19):1834-1844.

23. Gerstein HC, Colhoun HM, Dagenais GR, Diaz R, Lakshmanan M, Pais P, Probstfield J, Riesmeyer JS, Riddle MC, Rydén L et al: Dulaglutide and cardiovascular outcomes in type 2 diabetes (REWIND): a double-blind, randomised placebo-controlled trial. Lancet (London, England). 2019; 394(10193):121-130.

24. Marso SP, Nauck MA, Monk Fries T, Rasmussen S, Treppendahl MB, Buse JB: Myocardial Infarction Subtypes in Patients With Type 2 Diabetes Mellitus and the Effect of Liraglutide Therapy (from the LEADER Trial). Am J Cardiol. 2018; 121(12):1467-1470.

25. Garg A, Kumar A: Risk and Benefit Profile of Dulaglutide in Established Therapeutic Indication. Current drug safety. 2018; 13(3):165-170.

26. Holman RR, Bethel MA, Mentz RJ, Thompson VP, Lokhnygina Y, Buse JB, Chan JC, Choi J, Gustavson SM, Iqbal N et al: Effects of Once-Weekly Exenatide on Cardiovascular Outcomes in Type 2 Diabetes. The New England journal of medicine .2017; 377(13):1228-1239.

27. Hernandez AF, Green JB, Janmohamed S, D'Agostino RB, Sr., Granger CB, Jones NP, Leiter LA, Rosenberg AE, Sigmon KN, Somerville MC et al: Albiglutide and cardiovascular outcomes in patients with type 2 diabetes and cardiovascular disease (Harmony Outcomes): a double-blind, randomised placebo-controlled trial. Lancet (London, England). 2018; 392(10157):1519-1529.

28. Ahmann AJ, Capehorn M, Charpentier G, Dotta F, Henkel E, Lingvay I, Holst AG, Annett MP, Aroda VR: Efficacy and Safety of Once-Weekly Semaglutide Versus Exenatide ER in Subjects With Type 2 Diabetes (SUSTAIN 3): A 56-Week, Open-Label, Randomized Clinical Trial. Diabetes care. 2018; 41(2):258-266.

29. Pratley RE, Aroda VR, Lingvay I, Lüdemann I, Andreassen C, Navarria A Viljoen A: Semaglutide versus dulaglutide once weekly in patients with type 2 diabetes (SUSTAIN 7): a randomised, open-label, phase $3 \mathrm{~b}$ trial. The lancet Diabetes \& endocrinology. 2018; 6(4):275-286.
30. Capehorn MS, Catarig AM, Furberg JK, Janez A, Price HC, Tadayon S, Vergès B, Marre M: Efficacy and safety of once-weekly semaglutide $1.0 \mathrm{mg}$ vs once-daily liraglutide $1.2 \mathrm{mg}$ as add-on to $1-3$ oral antidiabetic drugs in subjects with type 2 diabetes (SUSTAIN 10). Diabetes \& metabolism. 2020; 46(2):100-109.

31. Russell-Jones D, Vaag A, Schmitz O, Sethi BK, Lalic N, Antic S, Zdravkovic M, Ravn GM, Simó R: Liraglutide vs insulin glargine and placebo in combination with metformin and sulfonylurea therapy in type 2 diabetes mellitus (LEAD-5 met+SU): a randomised controlled trial. Diabetologia. 2009' 52(10):2046-2055.

32. Wang W, Nevárez L, Filippova E, Song KH, Tao B, Gu L, Wang F, Li P, Yang J: Efficacy and safety of once-weekly dulaglutide versus insulin glargine in mainly Asian patients with type 2 diabetes mellitus on metformin and/or a sulphonylurea: A 52-week open-label, randomized phase III trial. Diabetes, obesity \& metabolism. 2019; 21(2):234-243.

33. Nauck MA, Meier JJ, Cavender MA, Abd El Aziz M, Drucker DJ: Cardiovascular Actions and Clinical Outcomes With Glucagon-Like Peptide-1 Receptor Agonists and Dipeptidyl Peptidase-4 Inhibitors. Circulation. 2017; 136(9):849-870.

34. Sun F, Wu S, Wang J, Guo S, Chai S, Yang Z, Li L, Zhang Y, Ji L, Zhan S: Effect of glucagon-like peptide-1 receptor agonists on lipid profiles among type 2 diabetes: a systematic review and network meta-analysis. Clin Ther. 2015; 37(1):225-241.e228

35. Anholm C, Kumarathurai P, Pedersen LR, Samkani A, Walzem RL, Nielsen OW, Kristiansen OP, Fenger M, Madsbad S, Sajadieh A et al: Liraglutide in combination with metformin may improve the atherogenic lipid profile and decrease C-reactive protein level in statin treated obese patients with coronary artery disease and newly diagnosed type 2 diabetes: A randomized trial. Atherosclerosis. 2019; 288:60-66.

36. Liu Y, Jiang X, Chen X: Liraglutide and Metformin alone or combined therapy for type 2 diabetes patients complicated with coronary artery disease. Lipids Health Dis. 2017; 16(1):227.

37. Buse JB, Drucker DJ, Taylor KL, Kim T, Walsh B, Hu H, Wilhelm K, Trautmann M, Shen LZ, Porter LE: DURATION-1: exenatide once weekly produces sustained glycemic control and weight loss over 52 weeks. Diabetes care. 2010; 33(6):1255-1261.

38. Weinstock RS, Guerci B, Umpierrez G, Nauck MA, Skrivanek Z, Milicevic Z: Safety and efficacy of once-weekly dulaglutide versus sitagliptin after 2 years in metformin-treated patients with type 2 diabetes (AWARD-5): a randomized, phase III study. Diabetes, obesity E metabolism. 2015; 17(9):849-858.

39. Bharucha AE, Charkoudian N, Andrews CN, Camilleri M, Sletten D, Zinsmeister AR, Low PA: Effects of glucagon-like peptide-1, yohimbine, and nitrergic modulation on sympathetic and parasympathetic activity in humans. American journal of physiology Regulatory, integrative and comparative physiology. 2008; 295(3):R874-880.

40. Gutzwiller JP, Tschopp S, Bock A, Zehnder CE, Huber AR, Kreyenbuehl M, Gutmann H, Drewe J, Henzen C, Goeke B et al: Glucagon-like peptide 1 induces natriuresis in healthy subjects and in insulin-resistant obese men. The Journal of clinical endocrinology and metabolism. 2004; 89(6):3055-3061.

41. Fiorentino TV, Casiraghi F, Davalli AM, Finzi G, La Rosa S, Higgins PB, Abrahamian GA, Marando A, Sessa F, Perego C et al: Exenatide regulates pancreatic islet integrity and insulin sensitivity in the nonhuman primate baboon Papio hamadryas. JCI insight .2019; 4(20).

42. Skov J, Dejgaard A, Frøkiær J, Holst JJ, Jonassen T, Rittig S, Christiansen JS: Glucagon-like peptide-1 (GLP-1): effect on kidney hemodynamics and renin-angiotensin-aldosterone system in healthy men. The Journal of clinical endocrinology and metabolism. 2013; 98(4):E664-671.

43. Jorsal A, Wiggers H, Holmager P, Nilsson B, Nielsen R, Boesgaard TW, Kumme A, Møller JE, Videbæk L, Kistorp C et al: A protocol for a randomised, double-blind, placebo-controlled study of the effect of LIraglutide on left VEntricular function in chronic heart failure patients with and without type 2 diabetes (The LIVE Study). BMJ open. 2014; 4(5):e004885

44. Sharma A, Ambrosy AP, DeVore AD, Margulies KB, McNulty SE, Mentz RI, Hernandez AF, Michael Felker G, Cooper LB, Lala A et al: Liraglutide and weight loss among patients with advanced heart failure and a reduced ejection fraction: insights from the FIGHT trial. ESC heart failure. 2018; 5(6):1035-1043.

45. Jorsal A, Kistorp C, Holmager P, Tougaard RS, Nielsen R, Hänselmann A Nilsson B, Møller JE, Hjort J, Rasmussen J et al: Effect of liraglutide, a glucagon-like peptide-1 analogue, on left ventricular function in stable chronic heart failure patients with and without diabetes (LIVE)-a multicentre, double-blind, randomised, placebo-controlled trial. European journal of heart failure. 2017; 19(1):69-77.

46. Tuttle KR, Lakshmanan MC, Rayner B, Busch RS, Zimmermann AG, Woodward DB, Botros FT: Dulaglutide versus insulin glargine in patients with type 2 diabetes and moderate-to-severe chronic kidney disease (AWARD-7): a multicentre, open-label, randomised trial. The lancet Diabetes $\mathcal{E}$ endocrinology. 2018; 6(8):605-617

47. Pfeffer MA, Claggett B, Diaz R, Dickstein K, Gerstein HC, Køber LV, Lawson FC, Ping L, Wei X, Lewis EF et al: Lixisenatide in Patients with Type 2 Diabetes and Acute Coronary Syndrome. The New England journal of medicine. 2015; 373(23):2247-2257

48. Nreu B, Dicembrini I, Tinti F, Sesti G, Mannucci E, Monami M: Major cardiovascular events, heart failure, and atrial fibrillation in patients treated with glucagon-like peptide-1 receptor agonists: An updated meta-analysis of randomized controlled trials. Nutrition, metabolism, and cardiovascular diseases : NMCD. 2020; 30(7):1106-1114. 
49. Sinha B, Ghosal S: Meta-analyses of the effects of DPP-4 inhibitors, SGLT2 inhibitors and GLP1 receptor analogues on cardiovascular death, myocardial infarction, stroke and hospitalization for heart failure. Diabetes research and clinical practice. $2019^{\prime}$ 150:8-16.

50. Singh AK, Singh R: Gender difference in cardiovascular outcomes with SGLT-2 inhibitors and GLP-1 receptor agonist in type 2 diabetes: A systematic review and meta-analysis of cardio-vascular outcome trials. Diabetes $\mathcal{E}$ metabolic syndrome. 2020' 14(3):181-187.

51. Monami M, Nreu B, Scatena A, Cresci B, Andreozzi F, Sesti G, Mannucci E: Safety issues with glucagon-like peptide-1 receptor agonists (pancreatitis, pancreatic cancer and cholelithiasis): Data from randomized controlled trials. Diabetes, obesity \& metabolism. 2017; 19(9):1233-1241.

52. Husain M, Birkenfeld AL, Donsmark M, Dungan K, Eliaschewitz FG, Franco DR, Jeppesen OK, Lingvay I, Mosenzon O, Pedersen SD et al: Oral Semaglutide and Cardiovascular Outcomes in Patients with Type 2 Diabetes. The New England journal of medicine. 2019; 381(9):841-851.

53. La Sala L, Prattichizzo F, Ceriello A: The link between diabetes and atherosclerosis. European journal of preventive cardiology. 2019; 26(2_suppl):15-24.

54. Ståhle M, Hellberg S, Virta J, Liljenbäck H, Metsälä O, Li XG, Jauhiainen M, Saukko P, Ylä-Herttuala S, Nuutila $\mathrm{P}$ et al: Evaluation of glucagon-like peptide-1 receptor expression in non-diabetic and diabetic atherosclerotic mice using PET tracer (68)Ga-NODAGA-exendin-4. American journal of physiology Endocrinology and metabolism. 2021.

55. Koshibu M, Mori Y, Saito T, Kushima H, Hiromura M, Terasaki M, Takada M, Fukui T, Hirano T: Antiatherogenic effects of liraglutide in hyperglycemic apolipoprotein E-null mice via AMP-activated protein kinase-independent mechanisms. American journal of physiology Endocrinology and metabolism. 2019; 316(5):E895-e907.

56. Jojima T, Uchida K, Akimoto K, Tomotsune T, Yanagi K, Iijima T, Suzuki K, Kasai K, Aso Y: Liraglutide, a GLP-1 receptor agonist, inhibits vascular smooth muscle cell proliferation by enhancing AMP-activated protein kinase and cell cycle regulation, and delays atherosclerosis in ApoE deficient mice. Atherosclerosis. 2017; 261:44-51.

57. Gaspari T, Liu H, Welungoda I, Hu Y, Widdop RE, Knudsen LB, Simpson RW, Dear AE: A GLP-1 receptor agonist liraglutide inhibits endothelial cell dysfunction and vascular adhesion molecule expression in an ApoE-/- mouse model. Diabetes \& vascular disease research.2011; 8(2):117-124.

58. Sudo M, Li Y, Hiro T, Takayama T, Mitsumata M, Shiomi M, Sugitani M, Matsumoto T, Hao H, Hirayama A: Inhibition of plaque progression and promotion of plaque stability by glucagon-like peptide-1 receptor agonist: Serial in vivo findings from iMap-IVUS in Watanabe heritable hyperlipidemic rabbits. Atherosclerosis. 2017; 265:283-291.

59. Gaspari T, Welungoda I, Widdop RE, Simpson RW, Dear AE: The GLP-1 receptor agonist liraglutide inhibits progression of vascular disease via effects on atherogenesis, plaque stability and endothelial function in an ApoE(-/-) mouse model. Diabetes $\mathcal{E}$ vascular disease research. 2013; 10(4):353-360.

60. Bisgaard LS, Bosteen MH, Fink LN, Sørensen CM, Rosendahl A, Mogensen CK, Rasmussen SE, Rolin B, Nielsen LB, Pedersen TX: Liraglutide Reduces Both Atherosclerosis and Kidney Inflammation in Moderately Uremic LDLr-/- Mice. PloS one .2016; 11(12):e0168396.

61. Hirata Y, Kurobe H, Nishio C, Tanaka K, Fukuda D, Uematsu E, Nishimoto S, Soeki T, Harada N, Sakaue H et al: Exendin-4, a glucagon-like peptide-1 receptor agonist, attenuates neointimal hyperplasia after vascular injury. European journal of pharmacology. 2013; 699(1-3):106-111.

62. Bjørnholm KD, Skovsted GF, Mitgaard-Thomsen A, Rakipovski G, Tveden-Nyborg P, Lykkesfeldt J, Povlsen GK: Liraglutide treatment improves endothelial function in the Ldlr-/- mouse model of atherosclerosis and affects genes involved in vascular remodelling and inflammation. Basic $\mathcal{E}$ clinical pharmacology \& toxicology. 2021; 128(1):103-114.

63. Wang Y, Parlevliet ET, Geerling JJ, van der Tuin SJ, Zhang H, Bieghs V, Jawad $\mathrm{AH}$, Shiri-Sverdlov R, Bot I, de Jager SC et al: Exendin-4 decreases liver inflammation and atherosclerosis development simultaneously by reducing macrophage infiltration. British journal of pharmacology. 2014; 171(3):723-734

64. Arakawa $M$, Mita $T$, Azuma $K$, Ebato $C$, Goto $H$, Nomiyama $T$, Fujitani $Y$, Hirose T, Kawamori R, Watada H: Inhibition of monocyte adhesion to endothelial cells and attenuation of atherosclerotic lesion by a glucagon-like peptide-1 receptor agonist, exendin-4. Diabetes. 2010; 59(4):1030-1037.

65. Bruen R, Curley $S$, Kajani S, Crean D, O'Reilly ME, Lucitt MB, Godson CG, McGillicuddy FC, Belton O: Liraglutide dictates macrophage phenotype in apolipoprotein E null mice during early atherosclerosis. Cardiovascular diabetology. 2017; 16(1):143.

66. Li J, Liu X, Fang Q, Ding M, Li C: Liraglutide attenuates atherosclerosis via inhibiting ER-induced macrophage derived microvesicles production in T2DM rats. Diabetology \& metabolic syndrome. 2017; 9:94.

67. Martins FL, Bailey MA, Girardi ACC: Endogenous Activation of Glucagon-Like Peptide-1 Receptor Contributes to Blood Pressure Control: Role of Proximal Tubule $\mathrm{Na}(+) / \mathrm{H}(+)$ Exchanger Isoform 3, Renal Angiotensin II, and Insulin Sensitivity. Hypertension (Dallas, Tex : 1979) .2020; 76(3):839-848.

68. Jensen EP, Møller S, Hviid AV, Veedfald S, Holst JJ, Pedersen J, Ørskov C, Sorensen CM: GLP-1-induced renal vasodilation in rodents depends exclusively on the known GLP-1 receptor and is lost in prehypertensive rats. American journal of physiology Renal physiology .2020; 318(6):F1409-f1417.

69. Ronn J, Jensen EP, Wewer Albrechtsen NJ, Holst JJ, Sorensen CM: Glucagon-like peptide-1 acutely affects renal blood flow and urinary flow rate in spontaneously hypertensive rats despite significantly reduced renal expression of GLP-1 receptors. Physiological reports; 2017; 5(23).

70. Baggio LL, Yusta B, Mulvihill EE, Cao X, Streutker CJ, Butany J, Cappola TP, Margulies KB, Drucker DJ: GLP-1 Receptor Expression Within the Human Heart. Endocrinology. 2018; 159(4):1570-1584.

71. Huang M, Wei R, Wang Y, Su T, Li Q, Yang X, Chen X: Protective effect of glucagon-like peptide-1 agents on reperfusion injury for acute myocardial infarction: a meta-analysis of randomized controlled trials. Annals of medicine. 2017; 49(7):552-561.

72. Chen J, Wang D, Wang F, Shi S, Chen Y, Yang B, Tang Y, Huang C: Exendin-4 inhibits structural remodeling and improves $\mathrm{Ca}(2+)$ homeostasis in rats with heart failure via the GLP-1 receptor through the eNOS/cGMP/PKG pathway. Peptides. 2017; 90:69-77.

73. Darwesh AM, El-Azab MF, Abo-Gresha NM, El-Sayed NM, Moustafa YM: Cardioprotective Mechanisms of Exenatide in Isoprenaline-induced Myocardial Infarction: Novel Effects on Myocardial a-Estrogen Receptor Expression and IGF-1/IGF-2 System. Journal of cardiovascular pharmacology. 2018; 71(3):160-173

74. Qiao H, Ren H, Du H, Zhang M, Xiong X, Lv R: Liraglutide repairs the infarcted heart: The role of the SIRT1/Parkin/mitophagy pathway. Molecular medicine reports. 2018: 17(3):3722-3734

75. Sassoon DJ, Tune JD, Mather KJ, Noblet JN, Eagleson MA, Conteh AM, Sturek JT, Goodwill AG: Glucagon-Like Peptide 1 Receptor Activation Augments Cardiac Output and Improves Cardiac Efficiency in Obese Swine After Myocardial Infarction. Diabetes. 2017; 66(8):2230-2240.

76. Robinson E, Cassidy RS, Tate M, Zhao Y, Lockhart S, Calderwood D, Church $\mathrm{R}$, McGahon MK, Brazil DP, McDermott BJ et al: Exendin-4 protects against post-myocardial infarction remodelling via specific actions on inflammation and the extracellular matrix. Basic research in cardiology. 2015; 110(2):20.

77. Chen J, Xu S, Zhou W, Wu L, Wang L, Li W: Exendin-4 Reduces Ventricular Arrhythmia Activity and Calcium Sparks-Mediated Sarcoplasmic Reticulum Ca Leak in Rats with Heart Failure. International heart journal. 2020; 61(1):145-152.

78. Zhou Y, He X, Chen Y, Huang Y, Wu L, He J: Exendin-4 attenuates cardiac hypertrophy via AMPK/mTOR signaling pathway activation. Biochemical and biophysical research communications. 2015; 468(1-2):394-399.

79. Nuamnaichati N, Mangmool S, Chattipakorn N, Parichatikanond W: Stimulation of GLP-1 Receptor Inhibits Methylglyoxal-Induced Mitochondrial Dysfunctions in H9c2 Cardiomyoblasts: Potential Role of Epac/PI3K/Akt Pathway. Frontiers in pharmacology. 2020; 11:805.

80. Wei H, Bu R, Yang Q, Jia J, Li T, Wang Q, Chen Y: Exendin-4 Protects against Hyperglycemia-Induced Cardiomyocyte Pyroptosis via the AMPK-TXNIP Pathway. Journal of diabetes research. 2019; 2019:8905917.

81. Li Q, Tuo X, Li B, Deng Z, Qiu Y, Xie H: Semaglutide attenuates excessive exercise-induced myocardial injury through inhibiting oxidative stress and inflammation in rats. Life sciences. 2020; 250:117531.

82. Yi B, Hu X, Wen Z, Zhang T, Cai Y: Exendin-4, a glucagon-like peptide-1 receptor agonist, inhibits hyperglycemia-induced apoptosis in myocytes by suppressing receptor for advanced glycation end products expression. Experimental and therapeutic medicine. 2014; 8(4):1185-1190.

83. Ding W, Chang WG, Guo XC, Liu Y, Xiao DD, Ding D, Wang JX, Zhang XJ: Exenatide Protects Against Cardiac Dysfunction by Attenuating Oxidative Stress in the Diabetic Mouse Heart. Frontiers in endocrinology. 2019; 10:202.

84. Almutairi M, Gopal K, Greenwell AA, Young A, Gill R, Aburasayn H, Al Batran R, Chahade JJ, Gandhi M, Eaton F et al: The GLP-1 Receptor Agonist Liraglutide Increases Myocardial Glucose Oxidation Rates via Indirect Mechanisms and Mitigates Experimental Diabetic Cardiomyopathy. The Canadian journal of cardiology. 2020.

85. Ji $\mathrm{Y}$, Zhao $\mathrm{Z}$, Cai $\mathrm{T}$, Yang $\mathrm{P}$, Cheng $\mathrm{M}$ : Liraglutide alleviates diabetic cardiomyopathy by blocking CHOP-triggered apoptosis via the inhibition of the IRE-a pathway. Molecular medicine reports. 2014; 9(4):1254-1258.

86. El-Kharashi OA, Mohamed DI, Khairy E, Ezzat SF, Zaki WS: Exenatide promotes cardiac IncRNAs HOX transcript antisense RNA (HOTAIR) in Wistar rats with liver cirrhosis; a novel role of GLP-1 receptor agonists in cirrhotic cardiomyopathy. European journal of pharmacology. 2019;855:294-304.

87. Wassef MAE, Tork OM, Rashed LA, Ibrahim W, Morsi H, Rabie DMM: Mitochondrial Dysfunction in Diabetic Cardiomyopathy: Effect of Mesenchymal Stem Cell with PPAR-y Agonist or Exendin-4. Experimental and clinical endocrinology $\mathcal{E}$ diabetes : official journal, German Society of Endocrinolooy [and] German Diabetes Association. 2018; 126(1):27-38.

88. Zhang Y, Ling Y, Yang L, Cheng Y, Yang P, Song X, Tang H, Zhong Y, Tang L, He $\mathrm{S}$ et al: Liraglutide relieves myocardial damage by promoting autophagy via AMPK-mTOR signaling pathway in zucker diabetic fatty rat. Molecular and cellular endocrinology.2017;448:98-107.

89. Qian P, Tian H, Wang Y, Lu W, Li Y, Ma T, Gao X, Yao W: A novel oral glucagon-like peptide 1 receptor agonist protects against diabetic cardiomyopathy via alleviating cardiac lipotoxicity induced mitochondria dysfunction. Biochemical pharmacology. 2020:114209.

90. Wu L, Wang K, Wang W, Wen Z, Wang P, Liu L, Wang DW: Glucagon-like peptide- 1 ameliorates cardiac lipotoxicity in diabetic cardiomyopathy via the PPARa pathway. Aging cell. 2018; 17(4):e12763.

91. Vinué Á, Navarro J, Herrero-Cervera A, García-Cubas M, Andrés-Blasco I, Martínez-Hervás S, Real JT, Ascaso JF, González-Navarro H: The GLP-1 analogue lixisenatide decreases atherosclerosis in insulin-resistant mice by modulating macrophage phenotype. Diabetologia. 2017; 60(9):1801-1812. 
92. Bruen R, Curley S, Kajani S, Lynch G, O'Reilly ME, Dillon ET, Brennan EP, Barry M, Sheehan S, McGillicuddy FC et al: Liraglutide Attenuates Preestablished Atherosclerosis in Apolipoprotein E-Deficient Mice via Regulation of Immune Cell Phenotypes and Proinflammatory Mediators. The Journal of pharmacology and experimental therapeutics. 2019; 370(3):447-458.

93. Tashiro Y, Sato K, Watanabe T, Nohtomi K, Terasaki M, Nagashima M, Hirano T: A glucagon-like peptide-1 analog liraglutide suppresses macrophage foam cell formation and atherosclerosis. Peptides. 2014; 54:19-26.

94. Inoue $T$, Inoguchi $T$, Sonoda N, Hendarto H, Makimura H, Sasaki S, Yokomizo H, Fujimura Y, Miura D, Takayanagi R: GLP-1 analog liraglutide protects against cardiac steatosis, oxidative stress and apoptosis in streptozotocin-induced diabetic rats. Atherosclerosis. 2015; 240(1):250-259.

95. Li P, Tang Z, Wang L, Feng B: Glucagon-like peptide-1 analogue liraglutide ameliorates atherogenesis via inhibiting advanced glycation end product-induced receptor for advanced glycosylation end product expression in apolipoprotein-E deficient mice. Molecular medicine reports. 2017; 16(3):3421-3426

96. Yang G, Lei Y, Inoue A, Piao L, Hu L, Jiang H, Sasaki T, Wu H, Xu W, Yu C et al: Exenatide mitigated diet-induced vascular aging and atherosclerotic plaque growth in ApoE-deficient mice under chronic stress. Atherosclerosis. 2017; 264:1-10.

97. Tang ST, Tang HQ, Su H, Wang Y, Zhou Q, Zhang Q, Wang Y, Zhu HQ: Glucagon-like peptide-1 attenuates endothelial barrier injury in diabetes via cAMP/PKA mediated down-regulation of MLC phosphorylation. Biomedicine E pharmacotherapy $=$ Biomedecine $\mathcal{E}$ pharmacotherapie. $2019 ; 113: 108667$

98. Tang ST, Zhang Q, Tang HQ, Wang CJ, Su H, Zhou Q, Wei W, Zhu HQ, Wang Y: Effects of glucagon-like peptide-1 on advanced glycation endproduct-induced aortic endothelial dysfunction in streptozotocin-induced diabetic rats: possible roles of Rho kinase- and AMP kinase-mediated nuclear factor $\mathrm{KB}$ signaling pathways. Endocrine. 2016; 53(1):107-116.

99. Guo N, Sun J, Chen H, Zhang H, Zhang Z, Cai D: Liraglutide prevents diabetes progression in prediabetic OLETF rats. Endocrine journal. 2013; 60(1):15-28.

100. Gaballah HH, Zakaria SS, Mwafy SE, Tahoon NM, Ebeid AM: Mechanistic insights into the effects of quercetin and/or GLP-1 analogue liraglutide on high-fat diet/streptozotocin-induced type 2 diabetes in rats. Biomedicine $\mathcal{E}$ pharmacotherapy = Biomedecine \& pharmacotherapie. 2017; 92:331-339.

101. Shao S, Nie M, Chen C, Chen X, Zhang M, Yuan G, Yu X, Yang Y: Protective action of liraglutide in beta cells under lipotoxic stress via PI3K/Akt/FoxO1 pathway. Journal of cellular biochemistry. 2014; 115(6):1166-1175.

102. Garber A, Henry R, Ratner R, Garcia-Hernandez PA, Rodriguez-Pattzi $H$ Olvera-Alvarez I, Hale PM, Zdravkovic M, Bode B: Liraglutide versus glimepiride monotherapy for type 2 diabetes (LEAD-3 Mono): a randomised, 52-week, phase III, double-blind, parallel-treatment trial. Lancet (London, England). 2009; 373(9662):473-481.

103. Al Batran R, Almutairi M, Ussher JR: Glucagon-like peptide-1 receptor mediated control of cardiac energy metabolism. Peptides. 2018; 100:94-100.

104. Koska J, Sands M, Burciu C, D'Souza KM, Raravikar K, Liu J, Truran S, Franco DA, Schwartz EA, Schwenke DC et al: Exenatide Protects Against Glucoseand Lipid-Induced Endothelial Dysfunction: Evidence for Direct Vasodilation Effect of GLP-1 Receptor Agonists in Humans. Diabetes. 2015; 64(7):2624-2635.

105. Wei R, Ma S, Wang C, Ke J, Yang J, Li W, Liu Y, Hou W, Feng X, Wang G et al: Exenatide exerts direct protective effects on endothelial cells through the AMPK/Akt/eNOS pathway in a GLP-1 receptor-dependent manner. American journal of physiology Endocrinology and metabolism. 2016; 310(11):E947-957.

106. Li AQ, Zhao L, Zhou TF, Zhang MQ, Qin XM: Exendin-4 promotes endothelial barrier enhancement via PKA- and Epac1-dependent Rac1 activation. American journal of physiology Cell physiology. 2015; 308(2):C164-175.

107. Yue W, Li Y, Ou D, Yang Q: The GLP-1 receptor agonist liraglutide protects against oxidized LDL-induced endothelial inflammation and dysfunction via KLF2. IUBMB life. 2019; 71(9):1347-1354.

108. Chang W, Zhu F, Zheng H, Zhou Z, Miao P, Zhao L, Mao Z: Glucagon-like peptide-1 receptor agonist dulaglutide prevents ox-LDL-induced adhesion of monocytes to human endothelial cells: An implication in the treatment of atherosclerosis. Mol Immunol. 2019; 116:73-79.

109. Cameron-Vendrig A, Reheman A, Siraj MA, Xu XR, Wang Y, Lei X, Afroze T, Shikatani E, El-Mounayri O, Noyan H et al: Glucagon-Like Peptide 1 Receptor Activation Attenuates Platelet Aggregation and Thrombosis. Diabetes. 2016; 65(6):1714-1723

110. Garczorz W, Gallego-Colon E, Kosowska A, Kłych-Ratuszny A, Woźniak M, Marcol W, Niesner KJ, Francuz T: Exenatide exhibits anti-inflammatory properties and modulates endothelial response to tumor necrosis factor a-mediated activation. Cardiovascular therapeutics. 2018; 36(2).

111. Luo X, Hu Y, He S, Ye Q, Lv Z, Liu J, Chen X: Dulaglutide inhibits high glucose- induced endothelial dysfunction and NLRP3 inflammasome activation. Arch Biochem Biophys. 2019; 671:203-209.

112. Zhao Q, Xu H, Zhang L, Liu L, Wang L: GLP-1 receptor agonist lixisenatide protects against high free fatty acids-induced oxidative stress and inflammatory response. Artif Cells Nanomed Biotechnol. 2019; 47(1):2325-2332.

113. Yang Y, Zhou Y, Wang Y, Wei X, Wu L, Wang T, Ma A: Exendin-4 reverses high glucose-induced endothelial progenitor cell dysfunction via SDF-13/CXCR7-AMPK/p38-MAPK/IL-6 axis. Acta diabetologica. 2020.
114. Yang $Y$, Zhou Y, Wang Y, Wei X, Wang T, Ma A: Exendin-4 regulates endoplasmic reticulum stress to protect endothelial progenitor cells from high-glucose damage. Molecular and cellular probes. 2020; 51:101527.

115. Cheng CK, Luo JY, Lau CW, Cho WC, Ng CF, Ma RCW, Tian XY, Huang Y: A GLP-1 analog lowers ER stress and enhances protein folding to ameliorate homocysteine-induced endothelial dysfunction. Acta pharmacologica Sinica. 2021.

116. Zhang Q, Xiao X, Zheng J, Li M: A glucagon-like peptide-1 analog, liraglutide, ameliorates endothelial dysfunction through miRNAs to inhibit apoptosis in rats. PeerI. 2019; 7:e6567.

117. Li Q, Yao Y, Shi S, Zhou M, Zhou Y, Wang M, Chiu JJ, Huang Z, Zhang W, Liu $M$ et al: Inhibition of miR-21 alleviated cardiac perivascular fibrosis via repressing EndMT in T1DM. Journal of cellular and molecular medicine. 2020; 24(1):910-920

118. Cooley BC, Nevado J, Mellad J, Yang D, St Hilaire C, Negro A, Fang F, Chen G, San $\mathrm{H}$, Walts AD et al: TGF- $\beta$ signaling mediates endothelial-to-mesenchymal transition (EndMT) during vein graft remodeling. Science translational medicine. 2014; 6(227):227ra234.

119. Tsai TH, Lee CH, Cheng CI, Fang YN, Chung SY, Chen SM, Lin CJ, Wu CJ, Hang CL, Chen WY: Liraglutide Inhibits Endothelial-to-Mesenchymal Transition and Attenuates Neointima Formation after Endovascular Injury in Streptozotocin-Induced Diabetic Mice. Cells. 2019; 8(6).

120. Guo C, Huang T, Chen A, Chen X, Wang L, Shen F, Gu X: Glucagon-like peptide 1 improves insulin resistance in vitro through anti-inflammation of macrophages. Braz J Med Biol Res. 2016; 49(12):e5826.

121. Takahashi H, Nomiyama T, Terawaki Y, Kawanami T, Hamaguchi Y, Tanaka T, Tanabe M, Bruemmer D, Yanase T: GLP-1 Receptor Agonist Exendin-4 Attenuates NR4A Orphan Nuclear Receptor NOR1 Expression in Vascular Smooth Muscle Cells. Journal of atherosclerosis and thrombosis. 2019; 26(2):183-197.

122. Zhou T, Zhang M, Zhao L, Li A, Oin X: Activation of Nrf2 contributes to the protective effect of Exendin-4 against angiotensin II-induced vascular smooth muscle cell senescence. American journal of physiology Cell physiology. 2016; 311(4):C572-c582.

123. Zhao L, Li AQ, Zhou TF, Zhang MQ, Qin XM: Exendin-4 alleviates angiotensin II-induced senescence in vascular smooth muscle cells by inhibiting Rac1 activation via a cAMP/PKA-dependent pathway. American journal of physiology Cell physiology. 2014; 307(12):C1130-1141.

124. Di B, Li HW, Li W, Hua B: Liraglutide inhibited AGEs induced coronary smooth muscle cell phenotypic transition through inhibiting the NF-kB signal pathway. Peptides. 2019; 112:125-132.

125. Liu Z, Zhang M, Zhou T, Shen Q, Qin X: Exendin-4 promotes the vascular smooth muscle cell re-differentiation through AMPK/SIRT1/FOXO3a signaling pathways. Atherosclerosis. 2018; 276:58-66.

126. Torres G, Morales PE, García-Miguel M, Norambuena-Soto I, Cartes-Saavedra B, Vidal-Peña G, Moncada-Ruff D, Sanhueza-Olivares F, San Martín A, Chiong M: Glucagon-like peptide-1 inhibits vascular smooth muscle cell dedifferentiation through mitochondrial dynamics regulation. Biochemical pharmacology. 2016; 104:52-61.

127. Xiong $X, \mathrm{Lu} \mathrm{W}$, Qin $X$, Luo Q, Zhou W: Downregulation of the GLP-1/CREB/adiponectin pathway is partially responsible for diabetes-induced dysregulated vascular tone and VSMC dysfunction. Biomedicine $\mathcal{E}$ pharmacotherapy = Biomedecine $\mathcal{E}$ pharmacotherapie. 2020; 127:110218.

128. Lee J, Hong SW, Kim MJ, Kwon H, Park SE, Rhee EJ, Lee WY: Metformin, resveratrol, and exendin-4 inhibit high phosphate-induced vascular calcification via AMPK-RANKL signaling. Biochemical and biophysical research communications. 2020; 530(2):374-380.

129. $\mathrm{Hu} \mathrm{XK}$, Yin $\mathrm{XH}$, Zhang HQ, Guo CF, Tang MX: Liraglutide attenuates the osteoblastic differentiation of MC3T3-E1 cells by modulating AMPK/mTOR signaling. Molecular medicine reports. 2016; 14(4):3662-3668.

130. Fan SH, Xiong OF, Wang L, Zhang LH, Shi YW: Glucagon-like peptide 1 treatment reverses vascular remodelling by downregulating matrix metalloproteinase 1 expression through inhibition of the ERK1/2/NF-KB signalling pathway. Molecular and cellular endocrinology. 2020:111005.

131. Feng L, Wang J, Ma X: Exogenous SERP1 attenuates restenosis by restoring GLP-1 receptor activity in diabetic rats following vascular injury. Biomedicine \& pharmacotherapy = Biomedecine $\mathcal{E}$ pharmacotherapie. 2018; 103:290-300.

132. Yu H, Rimbert A, Palmer AE, Toyohara T, Xia Y, Xia F, Ferreira LMR, Chen Z, Chen T, Loaiza $\mathrm{N}$ et al: GPR146 Deficiency Protects against Hypercholesterolemia and Atherosclerosis. Cell. 2019; 179(6):1276-1288.e1214.

133. Bułdak Ł, Machnik G, Bułdak RJ, Łabuzek K, Bołdys A, Okopień B: Exenatide and metformin express their anti-inflammatory effects on human monocytes/macrophages by the attenuation of MAPKs and NFKB signaling. Naunyn-Schmiedeberg's archives of pharmacology. 2016; 389(10):1103-1115.

134. Tanaka M, Matsuo Y, Yamakage H, Masuda S, Terada Y, Muranaka K, Wada H, Hasegawa K, Shimatsu A, Satoh-Asahara N: Differential effects of GLP-1 receptor agonist on foam cell formation in monocytes between non-obese and bese subjects. Metabolism: clinical and experimental. 2016; 65(2):1-11.

135. Dai Y, Dai D, Wang X, Ding Z, Li C, Mehta JL: GLP-1 agonists inhibit ox-LDL uptake in macrophages by activating protein kinase A. Journal of cardiovascular pharmacology. 2014; 64(1):47-52.

136. Wang YG, Yang TL: Liraglutide reduces oxidized LDL-induced oxidative stress and fatty degeneration in Raw 264.7 cells involving the AMPK/SREBP1 pathway. Journal of geriatric cardiology : JGC. 2015; 12(4):410-416. 
137. Wang N, Gao J, Jia M, Ma X, Lei Z, Da F, Yan F, Zhang H, Zhou Y, Li M et al: Exendin-4 Induces Bone Marrow Stromal Cells Migration Through Bone Marrow-Derived Macrophages Polarization via PKA-STAT3 Signaling Pathway. Cellular physiology and biochemistry: international journal of experimental cellular physiology, biochemistry, and pharmacology. 2017; 44(5):1696-1714.

138. Yang L, Chen L, Li D, Xu H, Chen J, Min X, He M, Wu T, Zhong J, Yang H et al: Effect of GLP-1/GLP-1R on the Polarization of Macrophages in the Occurrence and Development of Atherosclerosis. Mediators of inflammation. 2021; 2021:5568159.

139. Chen A, Chen Z, Xia Y, Lu D, Yang X, Sun A, Zou Y, Oian J, Ge J: Liraglutide attenuates NLRP3 inflammasome-dependent pyroptosis via regulating SIRT1/NOX4/ROS pathway in H9c2 cells. Biochemical and biophysical research communications. 2018; 499(2):267-272.

140. Shao N, Yu XY, Ma XF, Lin WJ, Hao M, Kuang HY: Exenatide Delays the Progression of Nonalcoholic Fatty Liver Disease in C57BL/6 Mice, Which May Involve Inhibition of the NLRP3 Inflammasome through the Mitophagy Pathway. Gastroenterology research and practice. 2018; 2018:1864307.

141. Yu X, Hao M, Liu Y, Ma X, Lin W, Xu Q, Zhou H, Shao N, Kuang H: Liraglutide ameliorates non-alcoholic steatohepatitis by inhibiting NLRP3 inflammasome and pyroptosis activation via mitophagy. European journal of pharmacology. 2019; 864:172715.

142. Xia J, Li Q, Liu Y, Ren Q, Gao J, Tian Y, Li J, Zhang B, Sun H, Liu S: A GLP-1 Analog Liraglutide Reduces Intimal Hyperplasia After Coronary Stent Implantation via Regulation of Glycemic Variability and NLRP3 Inflammasome/IL-10 Signaling in Diabetic Swine. Frontiers in pharmacology. 2020; 11:372.

143. Yusta B, Baggio LL, Koehler J, Holland D, Cao X, Pinnell LJ, Johnson-Henry KC, Yeung W, Surette MG, Bang KW et al: GLP-1R Agonists Modulate Enteric Immune Responses Through the Intestinal Intraepithelial Lymphocyte GLP-1R. Diabetes. 2015; 64(7):2537-2549.

144. He J, Lian C, Fang Y, Wu J, Zhou H, Ye X: The influence of exendin-4 intervention on -obese diabetic mouse blood and the pancreatic tissue immune microenvironment. Experimental and therapeutic medicine. 2016; 12(5):2893-2898.

145. He J, Kang Y, Lian C, Wu J, Zhou H, Ye X: Effect of miR-19b on the protective effect of Exendin-4 on islet cells in non-obese diabetic mice. Experimental and therapeutic medicine. 2019; 18(1):503-508.

146. Zhao Y, Xie Y, Li W: Liraglutide Exerts Potential Anti-inflammatory Effect in Type 1 Diabetes by Inhibiting IFN-ץ Production via Suppressing JAK-STAT Pathway. Endocrine, metabolic $\mathcal{E}$ immune disorders drug targets. 2019; 19(5):656-664

147. Huang J, Yi H, Zhao C, Zhang Y, Zhu L, Liu B, He P, Zhou M: Glucagon-like peptide-1 receptor (GLP-1R) signaling ameliorates dysfunctional immunity in COPD patients. International journal of chronic obstructive pulmonary disease. 2018; 13:3191-3202

148. Greaney JL, Surachman A, Saunders EFH, Alexander LM, Almeida DM: Greater Daily Psychosocial Stress Exposure is Associated With Increased Norepinephrine-Induced Vasoconstriction in Young Adults. Journal of the American Heart Association. 2020; 9(9):e015697.

149. Piao L, Zhao G, Zhu E, Inoue A, Shibata R, Lei Y, Hu L, Yu C, Yang G, Wu Het al: Chronic Psychological Stress Accelerates Vascular Senescence and Impairs Ischemia-Induced Neovascularization: The Role of Dipeptidyl Peptidase-4/Glucagon-Like Peptide-1-Adiponectin Axis. Journal of the American Heart Association. 2017; 6(10).

150. Cai X, She M, Xu M, Chen H, Li J, Chen X, Zheng D, Liu J, Chen S, Zhu J et al: GLP-1 treatment protects endothelial cells from oxidative stress-induced autophagy and endothelial dysfunction. International journal of biological sciences .2018;14(12):1696-1708.

151. Schisano B, Harte AL, Lois K, Saravanan P, Al-Daghri N, Al-Attas O, Knudsen LB, McTernan PG, Ceriello A, Tripathi G: GLP-1 analogue, Liraglutide protects human umbilical vein endothelial cells against high glucose induced endoplasmic reticulum stress. Regulatory peptides .2012; 174(1-3):46-52.

152. Fu Z, Mui D, Zhu H, Zhang Y: Exenatide inhibits NF-kB and attenuates ER stress in diabetic cardiomyocyte models. Aging. 2020;12(9):8640-8651.

153. Lu K, Chang G, Ye L, Zhang P, Li Y, Zhang D: Protective effects of extendin-4 on hypoxia/reoxygenation-induced injury in $\mathrm{H} 9 \mathrm{c} 2$ cells. Molecular medicine reports. 2015; 12(2):3007-3016

154. Chang G, Zhang D, Yu H, Zhang P, Wang Y, Zheng A, Qin S: Cardioprotective effects of exenatide against oxidative stress-induced injury. International journal of molecular medicine. 2013; 32(5):1011-1020.

155. Zhao SM, Gao HL, Wang YL, Xu Q, Guo CY: Attenuation of High Glucose-Induced Rat Cardiomyocyte Apoptosis by Exendin-4 via Intervention of HO-1/Nrf-2 and the PI3K/AKT Signaling Pathway. The Chinese journal of physiology. 2017; 60(2):89-96.

156. Zhang L, Li C, Zhu Q, Li N, Zhou H: Liraglutide, a glucagon-like peptide-1 analog, inhibits high glucose-induced oxidative stress and apoptosis in neonatal rat cardiomyocytes. Experimental and therapeutic medicine. 2019; 17(5):3734-3740

157. Cao YY, Chen ZW, Gao YH, Wang XX, Ma JY, Chang SF, Qian JY, Ge JB: Exenatide Reduces Tumor Necrosis Factor-a-induced Apoptosis in Cardiomyocytes by Alleviating Mitochondrial Dysfunction. Chinese medical journal. 2015; 128(23):3211-3218.

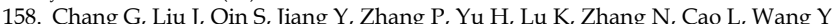
et al: Cardioprotection by exenatide: A novel mechanism via improving mitochondrial function involving the GLP-1 receptor/cAMP/PKA pathway. International journal of molecular medicine. 2018; 41(3):1693-1703.
159. Wu J, Xie F, Oin $Y$, Liu J, Yang $Z$ : Notch signaling is involved in the antiapoptotic effects of liraglutide on rat $\mathrm{H} 9 \mathrm{c} 2$ cardiomyocytes exposed to hypoxia followed by reoxygenation. The Journal of international medical research. 2020; 48(9):300060520948394.

160. Wang D, Jiang L, Feng B, He N, Zhang Y, Ye H: Protective effects of glucagon-like peptide- 1 on cardiac remodeling by inhibiting oxidative stress through mammalian target of rapamycin complex $1 /$ p70 ribosomal protein S6 kinase pathway in diabetes mellitus. Journal of diabetes investigation. 2020; 11(1):39-51.

161. XiaoTian L, QiNan W, XiaGuang G, WuQuan D, Bing C, ZiWen L: Exenatide Activates the APPL1-AMPK-PPARa Axis to Prevent Diabetic Cardiomyocyte Apoptosis. Journal of diabetes research. 2016; 2016:4219735.

162. Okabe K, Matsushima S, Ikeda S, Ikeda M, Ishikita A, Tadokoro T, Enzan N, Yamamoto T, Sada M, Deguchi H et al: DPP (Dipeptidyl Peptidase)-4 Inhibitor Attenuates Ang II (Angiotensin II)-Induced Cardiac Hypertrophy via GLP (Glucagon-Like Peptide)-1-Dependent Suppression of Nox (Nicotinamide Adenine Dinucleotide Phosphate Oxidase) 4-HDAC (Histone Deacetylase) 4 Pathway. Hypertension (Dallas, Tex : 1979. 2020; 75(4):991-1001.

163. Zheng RH, Bai XJ, Zhang WW, Wang J, Bai F, Yan CP, James EA, Bose HS, Wang NP, Zhao ZQ: Liraglutide attenuates cardiac remodeling and improves eart function after abdominal aortic constriction through blocking angiotensin II type 1 receptor in rats. Drug design, development and therapy. 2019; 13:2745-2757.

164. Hu SY, Zhang Y, Zhu PJ, Zhou H, Chen YD: Liraglutide directly protects cardiomyocytes against reperfusion injury possibly via modulation of intracellular calcium homeostasis. Journal of geriatric cardiology : JGC. 2017; 14(1):57-66.

165. Ang R, Mastitskaya S, Hosford PS, Basalay M, Specterman M, Aziz Q, Li Y, Orini M, Taggart P, Lambiase PD et al: Modulation of Cardiac Ventricular Excitability by GLP-1 (Glucagon-Like Peptide-1). Circulation Arrhythmia and electrophysiology. 2018; 11(10):e006740.

166. Bai XJ, Hao JT, Zheng RH, Yan CP, Wang J, Yang CH, Zhang WF, Zhao ZQ: Glucagon-Like Peptide-1 Analog Liraglutide Attenuates Pressure-Overload Induced Cardiac Hypertrophy and Apoptosis through Activating ATP Sensitive Potassium Channels. Cardiovascular drugs and therapy. 2020.

167. Zhao T, Chen H, Cheng C, Zhang J, Yan Z, Kuang J, Kong F, Li C, Lu Q: Liraglutide protects high-glucose-stimulated fibroblasts by activating the CD36-JNK-AP1 pathway to downregulate P4HA1. Biomedicine $\mathcal{E}$ pharmacotherapy = Biomedecine \& pharmacotherapie. 2019; 118:109224.

168. Chen P, Yang F, Wang W, Li X, Liu D, Zhang Y, Yin G, Lv F, Guo Z, Mehta JL et al: Liraglutide Attenuates Myocardial Fibrosis via Inhibition of AT1R-Mediated ROS Production in Hypertensive Mice. Journal of cardiovascular pharmacology and therapeutics. 2021; 26(2):179-188.

169. Wang XW, Zhang FX, Yang F, Ding ZF, Agarwal N, Guo ZK, Mehta JL: Effects of linagliptin and liraglutide on glucose- and angiotensin II-induced collagen formation and cytoskeleton degradation in cardiac fibroblasts in vitro. Acta pharmacologica Sinica. 2016; 37(10):1349-1358.

170. Caruso I, Cignarelli A, Giorgino F: Heterogeneity and Similarities in GLP-1 Receptor Agonist Cardiovascular Outcomes Trials. Trends in endocrinology and metabolism: TEM. 2019; 30(9):578-589.

171. Mody R, Yu M, Nepal B, Konig M, Grabner M: Adherence and persistence among patients with type 2 diabetes initiating dulaglutide compared with semaglutide and exenatide BCise: 6-month follow-up from US real-world data. Diabetes, obesity \& metabolism. 2020.

172. Gelhorn HL, Bacci ED, Poon JL, Boye KS, Suzuki S, Babineaux SM: Evaluating preferences for profiles of glucagon-like peptide- 1 receptor agonists among injection-naive type 2 diabetes patients in Japan. Patient preference and adherence. 2016; 10:1337-1348.

173. Koska J, Migrino RQ, Chan KC, Cooper-Cox K, Reaven PD: The Effect of Exenatide Once Weekly on Carotid Atherosclerosis in Individuals With Type 2 Diabetes: An 18-Month Randomized Placebo-Controlled Study. Diabetes care. 2021.

174. Scheen AJ: GLP-1 receptor agonists and heart failure in diabetes. Diabetes $\mathcal{E}$ metabolism. 2017; 43 (Suppl 1):2s13-12s19.

175. Leiter LA, Bain SC, Bhatt DL, Buse JB, Mazer CD, Pratley RE, Rasmussen S, Ripa MS, Vrazic H, Verma S: The effect of glucagon-like peptide-1 receptor agonists liraglutide and semaglutide on cardiovascular and renal outcomes across baseline blood pressure categories: Analysis of the LEADER and SUSTAIN 6 trials. Diabetes, obesity \& metabolism. 2020.

176. Liu Y, Morley M, Brandimarto J, Hannenhalli S, Hu Y, Ashley EA, Tang WH, Moravec CS, Margulies KB, Cappola TP et al: RNA-Seq identifies novel myocardial gene expression signatures of heart failure. Genomics. 2015; 105(2):83-89.

177. Koentges C, Pepin ME, Müsse C, Pfeil K, Alvarez SVV, Hoppe N, Hoffmann MM, Odening KE, Sossalla S, Zirlik A et al: Gene expression analysis to identify mechanisms underlying heart failure susceptibility in mice and humans. Basic research in cardiology. 2018; 113(1):8.

178. Gao H, Niu G, Yang M, Quan Q, Ma Y, Murage EN, Ahn JM, Kiesewetter DO, Chen X: PET of insulinoma using 18F-FBEM-EM3106B, a new GLP-1 analogue. Mol Pharm. 2011; 8(5):1775-1782.

179. Kiesewetter DO, Gao H, Ma Y, Niu G, Quan Q, Guo N, Chen X: 18Fradiolabeled analogs of exendin-4 for PET imaging of GLP-1 in insulinoma. Eur J Nucl Med Mol Imagin. 2012; 39(3):463-473. 
180. Gao H, Kiesewetter DO, Zhang X, Huang X, Guo N, Lang L, Hida N, Wang H, Wang H, Cao F et al: PET of glucagonlike peptide receptor upregulation after myocardial ischemia or reperfusion injury. J Nucl Med. 2012; 53(12):1960-1968.

181. Kiesewetter DO, Guo N, Guo J, Gao H, Zhu L, Ma Y, Niu G, Chen X: Evaluation of an [(18)F]AlF-NOTA Analog of Exendin-4 for Imaging of GLP-1 Receptor in Insulinoma. Theranostics. 2012; 2(10):999-1009.

182. Yue X, Kiesewetter DO, Guo J, Sun Z, Zhang X, Zhu L, Niu G, Ma Y, Lang L, Chen $X$ : Development of a new thiol site-specific prosthetic group and its conjugation with [Cys(40)]-exendin-4 for in vivo targeting of insulinomas. Bioconjug Chem. 2013; 24(7):1191-1200.

183. Sun Z, Tong G, Kim TH, Ma N, Niu G, Cao F, Chen X: PEGylated exendin-4, a modified GLP-1 analog exhibits more potent cardioprotection than its unmodified parent molecule on a dose to dose basis in a murine model of myocardial infarction. Theranostics. 2015; 5(3):240-250.

184. Zhang M, Jacobson O, Kiesewetter DO, Ma Y, Wang Z, Lang L, Tang L, Kang F, Deng H, Yang W et al: Improving the Theranostic Potential of Exendin 4 by Reducing the Renal Radioactivity through Brush Border Membrane Enzyme-Mediated Degradation. Bioconjug Chem. 2019; 30(6):1745-1753.

185. Niu G, Wang G, Lau J, Lang L, Jacobson O, Ma Y, Kiesewetter DO, Zhang S, Chen X: Antidiabetic Effect of Abextide, a Long-Acting Exendin-4 Analogue in Cynomolgus Monkeys. Adv Healthc Mater. 2019; 8(12):e1800686.

186. Liu Y, Wang G, Zhang H, Ma Y, Lang L, Jacobson O, Kiesewetter DO, Zhu L, Gao S, Ma Q et al: Stable Evans Blue Derived Exendin-4 Peptide for Type 2 Diabetes Treatment. Bioconjug Che. 2016; 27(1):54-58.

187. Patel A, MacMahon S, Chalmers J, Neal B, Billot L, Woodward M, Marre M, Cooper M, Glasziou P, Grobbee D et al: Intensive blood glucose control and vascular outcomes in patients with type 2 diabetes. The New England journal of medicine. 2008; 358(24):2560-2572.

188. Gerstein HC, Miller ME, Byington RP, Goff DC, Jr., Bigger JT, Buse JB, Cushman WC, Genuth S, Ismail-Beigi F, Grimm RH, Jr. et al: Effects of intensive glucose lowering in type 2 diabetes. The New England journal of medicine. 2008; 358(24):2545-2559.

189. Morovatdar N, Poorzand H, Bondarsahebi Y, Hozhabrossadati SA, Montazeri S, Sahebkar A: Water pipe tobacco smoking and risk of Coronary Artery Disease: A systematic review and meta-analyses. Current Molecular Pharmacology. 2020

190. Cukierman-Yaffe T, Gerstein HC, Colhoun HM, Diaz R, García-Pérez LE, Lakshmanan M, Bethel A, Xavier D, Probstfield J, Riddle MC et al: Effect of dulaglutide on cognitive impairment in type 2 diabetes: an exploratory analysis of the REWIND trial. The Lancet Neurology. 2020; 19(7):582-590. 